\title{
钯催化的串联反应构建苯并五元杂环的研究进展
}

\author{
丁 刚 ${ }^{a, b}$ 王泽宇 ${ }^{a}$ 殷中琼 ${ }^{c}$ 乐贵洲*,a,b \\ $\left({ }^{a}\right.$ 四川农业大学理学院 雅安 625014)

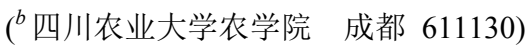 \\ $\left({ }^{c}\right.$ 四川农业大学动物医学院 成都 611130)
}

\begin{abstract}
摘要 苯并五元杂环是许多重要天然产物的骨架之一. 近年来, 过渡金属催化的串联反应能够在 “一锅煮” 的条件下 构建多根化学键, 其中钯催化的串联反应受到广泛关注. 总结了自 2000 年以来钯催化的串联反应合成苯并五元杂环及 其衍生物的文献.
\end{abstract}

关键词 杂环; 串联反应; 钯催化剂; 合成

\section{Progress in Palladium-Catalyzed Tandem Reaction of Constructing Benzo-Five-Membered Heterocycles}

\author{
Ding, Gang ${ }^{a, b} \quad$ Wang, Zeyu $^{a} \quad$ Yin, Zhongqiong $^{c} \quad$ Yue, Guizhou* ${ }^{*, a, b}$ \\ ( ${ }^{a}$ College of Science, Sichuan Agricultural University, Ya'an, 625014) \\ ( ${ }^{b}$ College of Agricultural Sciences, Sichuan Agricultural University, Chengdu 611130) \\ ( ${ }^{c}$ College of Veterinary Medicine, Sichuan Agricultural University, Chengdu 611130)
}

\begin{abstract}
The benzo-five-membered heterocycles existed extensively in many important natural products and also showed excellent bioactivites. Therefore, organic chemists around the world made efforts to develop the highly efficient methods of constructing these heterocycles. Recently, the syntheses of them via transition metal-catalyzed tandem reaction, especially palladium-catalyzed reaction, have been reported widely. This review emphasizes on the palladium-catalyzed tandem reaction of the formation of benzo-five-membered heterocycles and their derivatives reported since 2000.

Keywords heterocycle; tandem reaction; palladium catalyst; synthesis
\end{abstract}

具有苯并五元杂环骨架结构的天然产物大多具有 重要的生理活性 ${ }^{[1,2]}$, 从而被广泛应用于医药、农药等领 域. 因此, 发展高效、快速的构建苯并五元环骨架的方 法势在必行, 这也是当前有机化学研究热点之一.

近年来, 过渡金属催化形成碳碳键及碳杂键的偶联 反应得到蓬勃发展 ${ }^{[3 \sim 9]}$. 其中有机卤代物或拟卤代物(I, $\mathrm{Br}, \mathrm{Cl}, \mathrm{OTf}, \mathrm{NTf}$ 等)在钯等过渡金属催化下可以与烯烃 (Heck)、炔烃(Sonogashira)、有机嗍 (Suzuki)、有机锡 (Stille)、有机硅(Hiyama)、有机锌(Negishi)及格氏试剂 (Kumada)等反应来有效地构筑碳碳键, 同样形成碳氮键 的 Buchwald-Hartwig 偶联反应也受到广泛的关注 ${ }^{[10 \sim 13]}$. 近年来, 羰基 $\alpha$ 位的芳基化 ${ }^{[14]}$ 及芳基的 $\mathrm{C}-\mathrm{H}$ 活化 ${ }^{[15,16]}$ 也得到快速发展. 关于构建苯并五元杂环骨架的方法已
有广泛研究，近年来有关于这方面的文献有较多报道， 所用催化剂有 $\mathrm{Cu}^{[17]}, \mathrm{Ti}^{[18]}, \mathrm{Ag}^{[19]}, \mathrm{Ru}^{[20]}, \mathrm{Pd}^{[21]}$ 等. 而钯催 化串联合成苯并五元杂环化合物的研究只有少量综述 涉及 ${ }^{[22 ~ 25]}$. 相比其它过渡金属, 钯具有与众多官能团的 兼容性，优异的立体、区域选择性以及高效的催化活性 等优点. 因此, 本文选择从钯参与的串联反应构建苯并 五元杂环的角度出发, 对最近 15 年的相关文献按反应 类型加以分类, 并给予总结及评论.

\section{1 钯催化的环化/偶联反应}

\section{1 环化/Stille 偶联}

钯催化炔烃与三丁基锡氢在室温下便可制备各种 有机锡试剂, 并且它能够在空气中存放, 因此有机锡试

\footnotetext{
*E-mail: yueguizhou@sicau.edu.cn

Received August 10, 2015; revised November 2, 2015; published online November 6, 2015

Project supported by the Science \& Technology Department of Sichuan Province (No. 2012JY0118) and the Sichuan Agricultural University.

四川省科技厅应用基础项目基金(No. 2012JY0118)和四川农业大学资助项目.
} 
剂参与的 Stille 偶联在合成中被广泛应用.

2000 年, Grigg 小组 ${ }^{[26]}$ 以邻碘烯基苯和有机锡试剂 作为反应底物, 通过钯参与的环化/Stille 串联反应得到 3-取代二氢吲哚及苯并二氢呋喃衍生物(Scheme 1). 反 应的可能机理是: 原位生成的 $\operatorname{Pd}(0)$ 对 $\mathrm{C}$ - I 键进行氧化 加成, 接着对双键进攻并环化形成钯复合物, 最后该复 合物再与有机锡试剂完成转金属化, 还原消除形成最终 产物. 同年, 该小组 ${ }^{[27]}$ 将含有核苷、糖基、嘌呤等基团 的有机锡试剂，进行相同反应也得到 15 个类似产物. 在 反应中添加季铵盐可以提高产率, 主要是由于季铵阳离 子对环化过程起加速作用, 同时其阴离子可稳定钯中间 体 $^{[28]}$.

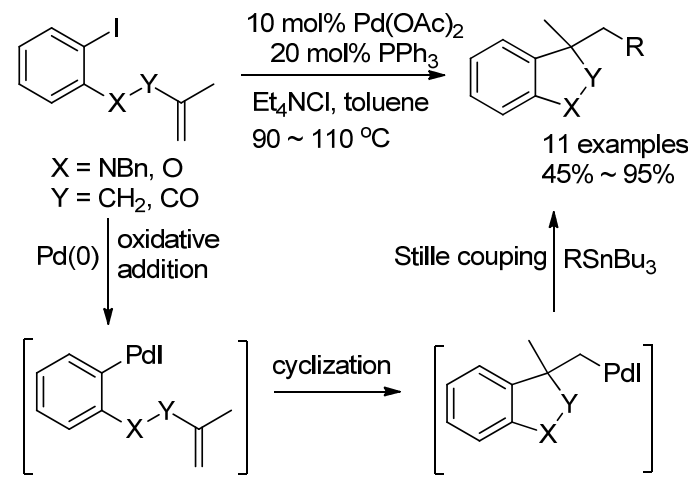

图式 1 环化/Stille 串联反应

Scheme 1 Tandem cyclization/Stille coupling

接着, 该小组 ${ }^{[29]}$ 尝试将接有 $\mathrm{Bu}_{3} \mathrm{Sn}$ 基团的二烯碘代 物进行这类反应. 反应经两次环化后, 也成功地得到一 系列含苯并五元杂环的螺环(Eq. 1)及桥环衍生物(Eq. 2). 相比 $\mathrm{Et}_{4} \mathrm{NCl}$, 添加 $\mathrm{Ag}_{2} \mathrm{CO}_{3}$ 更有利于反应. 这可能是因 为银盐能抑制双键的异构化. 随后, 该小组 ${ }^{[30]}$ 以 Wang 树脂作为载体实现了这类反应的固相合成(SPOS). 相比 传统液相合成, 固相合成操作简便、产物易分离提纯、 产率较高、环境污染较少，且容易实现制动化控制等.
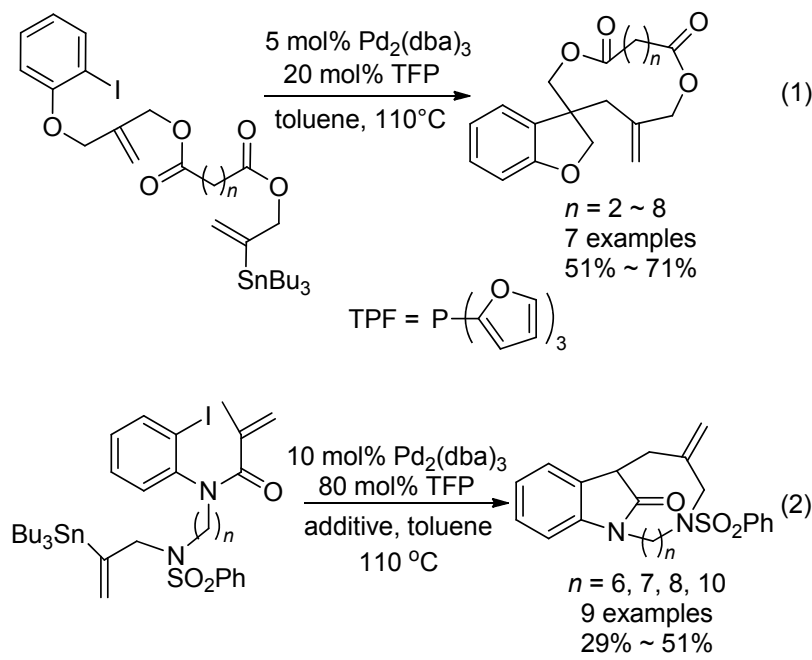

2006 年，他们 ${ }^{[31]}$ 又研究了钯催化氨基甲酰氯与炔 基的分子内反应来构建二氢吲哚衍结构(Eq. 3). 反应经 历 5-exo-dig 环化/Stille 偶联得到 $\alpha, \beta$-酰胺化合物.

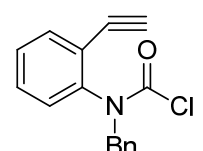

Bn

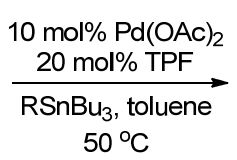

$50{ }^{\circ} \mathrm{C}$

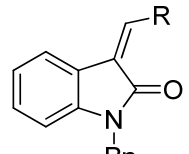

$\mathrm{Bn}$

3 examples $76 \% \sim 88 \%$
2007 年, Lamaty 小组 ${ }^{[32]}$ 报道了缺电子烯烃的串联 反应(Eq. 4). 他们发现添加 1,3-二甲基-2-咪唑啉酮 (DMI)能有效地抑制有机锡试剂的自身偶联.

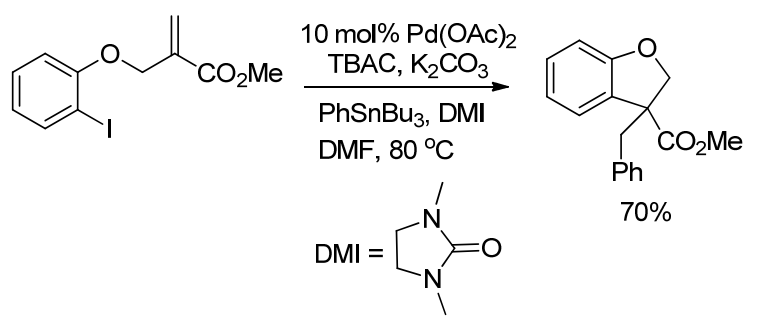

\section{2 环化/Suzuki 偶联}

尽管有机基锡试剂应用广，但造价高、毒性大，逐 渐被低毒性的试剂所取代，其中有机硼试剂就是一个不 错的选择. 它毒性小、易制备、生成易溶于水的副产物, 大多数对水、空气和热都很稳定. 目前已有许多商品化 的有机嗍试剂，因此相比有机锡它具有更加广阔的应用 前景.

2001 年, Grigg 小组 ${ }^{[33]}$ 报道了多组分的钯催化串联 反应(Scheme 2). 他们以 2-碘噻吩、丙二烯、邻碘苯胺 为原料, 在四三苯基膦钯的催化下，2-碘噻吩首先被氧 化加成, 接着形成的钯中间体与联烯反应得到烯丙基钯 物种，它再与邻碘苯胺发生胺化反应形成叔胺，最后添 加有机硼试剂后, 发生环化/Suzuki 偶联得到最终产物.

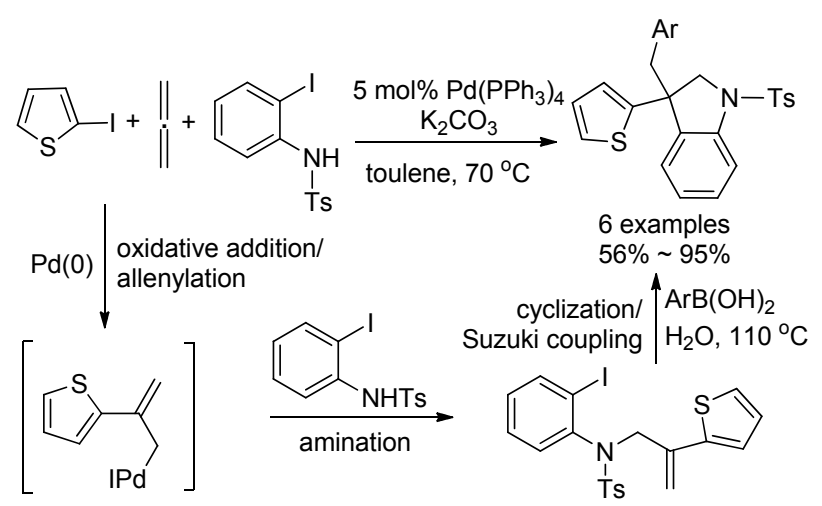

图式 2 环化/Suzuki 串联反应

Scheme 2 Tandem cyclization/Suzuki coupling 
2003 年, Lamaty 小组 ${ }^{[34]}$ 研究了另一类多组分体系. 邻碘苯酚对 2-溴烯丙酸酯的亲核取代, 得到缺电子烯 烃, 该中间体经历环化/Suzuki 偶联, 产率仅有 $57 \%$. 2007 年, 该小组 ${ }^{[32]}$ 在原有基础上进行了更深入的研究, 将中间产物分离出来进行反应(Eq. 5), 总产率比之前有 所增加. 值得注意的是, 加入 $\mathrm{PPh}_{3}$ 配体反而会降低反应 速率.

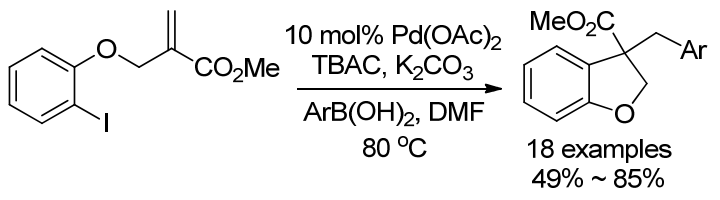

2005 年, Takemoto 小组 ${ }^{[35]}$ 研究了芳基碘与参键环 化/Suzuki 偶联的反应(Eq. 6). 底物以 5-exo-dig 方式环化 得烯基钯复合物后, 再与有机硼试剂进行 Suzuki 偶联形 成单一的 $E$ 式构型产物. 研究发现, 添加 $\mathrm{CsF}$ 有助于 Suzuki 偶联, 芳基嗍酸中可以带有吸电子、供电子及大 位阻的基团, 此外该反应还具有底物兼容性好等优点.

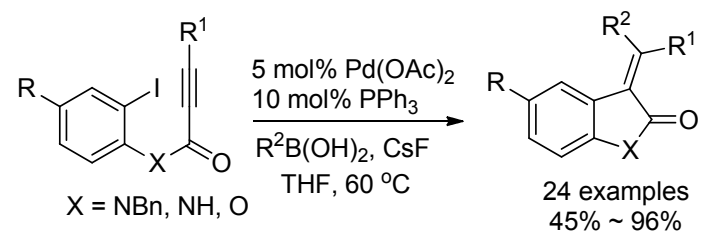

2014 年, Sridharan 小组 ${ }^{[36]}$ 使用 $\mathrm{Cu} / \mathrm{Pd}$ 双金属体系催 化 $N$-炔基酰胺合成 $N$-三唑二氢吲哚酩(Scheme 3). 首 先, $\mathrm{Cu}(\mathrm{I})$ 催化参键与叠氮化物的 Click 反应, 生成三唑 类化合物; 随后, 钯催化三唑化合物发生分子内环化/ Suzuki 偶联得终产物.

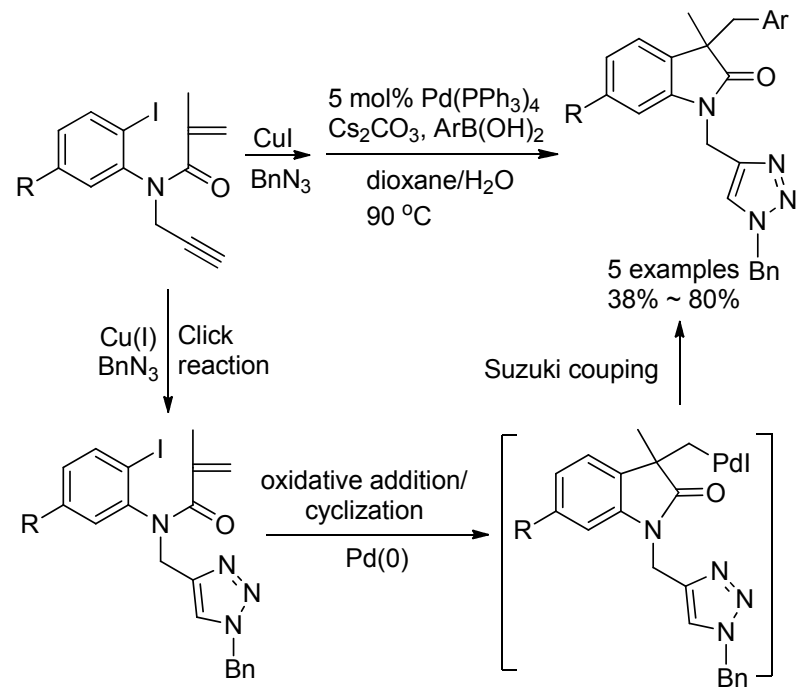

图式 3 铜/钯双金属催化的串联反应

Scheme $3 \mathrm{Cu} / \mathrm{Pd}$ bimetal-catalyzed tandem reaction

\section{3 环化/Heck 反应}

Takemoto 小组 ${ }^{[35]}$ 报道了炔酰胺与烯烃的环化/Heck 反应(Scheme 4). 与之前报道的环化/Suzuki 偶联反应类 似(Eq. 6), 经历相同的环化步骤, 接着与烯烃发生 Heck 反应生成 $\alpha, \delta$-不饱和酰胺.
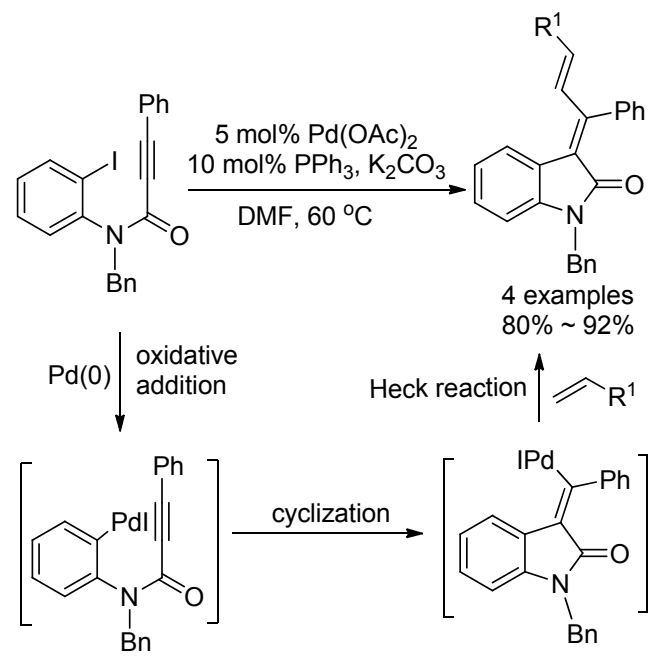

图式 4 环化/Heck 串联反应

Scheme 4 Tandem cyclization/Heck coupling

2007 年, Liu 等 ${ }^{[37]}$ 报道了有水存在、不需要配体的 还原 Heck 反应(Eq. 7). 水在这个反应中是必要的, 但过 多的水 $(>5 \%)$ 则会抑制环化反应，从而产生更多副产 物. 正是由于不怕水的特点, 该反应为进行放大试验提 供了可行性.

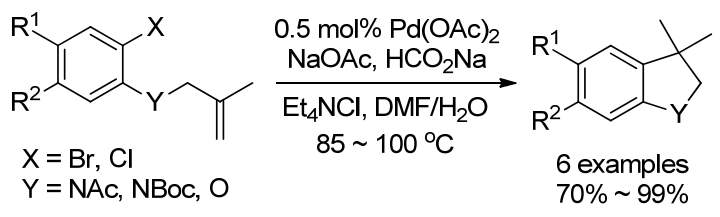

2009 年, Kim 小组 ${ }^{[38]}$ 报道的还原 Heck 反应, 产率为 $47 \% \sim 80 \%$ (Eq. 8). 2015 年, Day 等 ${ }^{[39]}$ 报道的这类反应不 仅可以在苯环上引入卤素, 而且氮原子上不需要取代 基. 此外含氮的芳杂环也可发生反应.

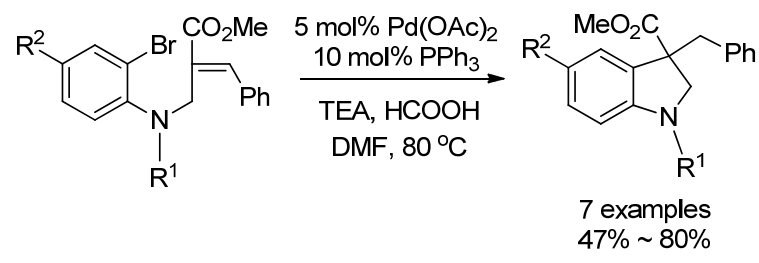

\section{4 环化/胺化反应}

2002 年, Grigg 小组 ${ }^{[40]}$ 研究了环化/联烯化/胺化的多 组分反应(Scheme 5 和 Eq. 9). 反应以丙二烯、取代碘苯、 胺等为原料, 在 $\mathrm{Pd}(\mathrm{OAc})_{2}$ 的催化作用下, 取代碘苯经环 
化后接着对丙二烯的插入得到烯丙基钯, 最后它通过胺 化反应形成 $\mathrm{C}-\mathrm{N}$ 键而得产物.
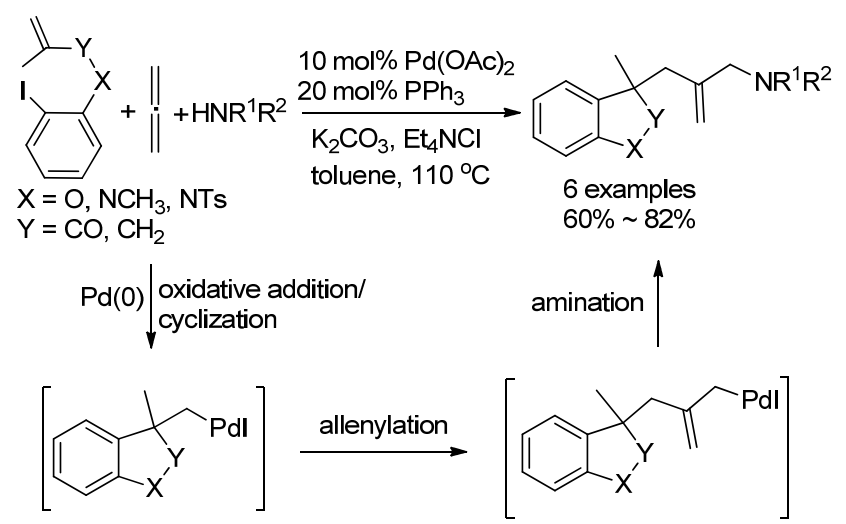

图式 5 环化/胺化串联反应

Scheme 5 Tandem cyclization/amination

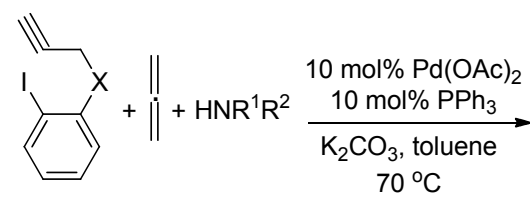

$\mathrm{X}=\mathrm{O}, \mathrm{NSO}_{2} \mathrm{Ph}$

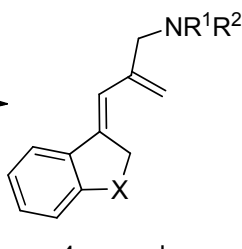

4 examples
$60 \% \sim 67 \%$
(9)

2010 年, 祝介平小组 ${ }^{[41]}$ 对钯催化串联合成吲哚螺 环衍生物的反应进行了报道, 反应包括环化及分子内的 胺化反应(Eqs. 10 和 11). 研究发现, 配体的选择至关重 要, $t$-BuMephos 配体不仅可以促进螺环的形成, 而且使 反应具有好的选择性, 得到单一的非对映体异构体. 该 方法为合成螺环结构的二氢吲哚类天然产物提供了一 种很好的途径.
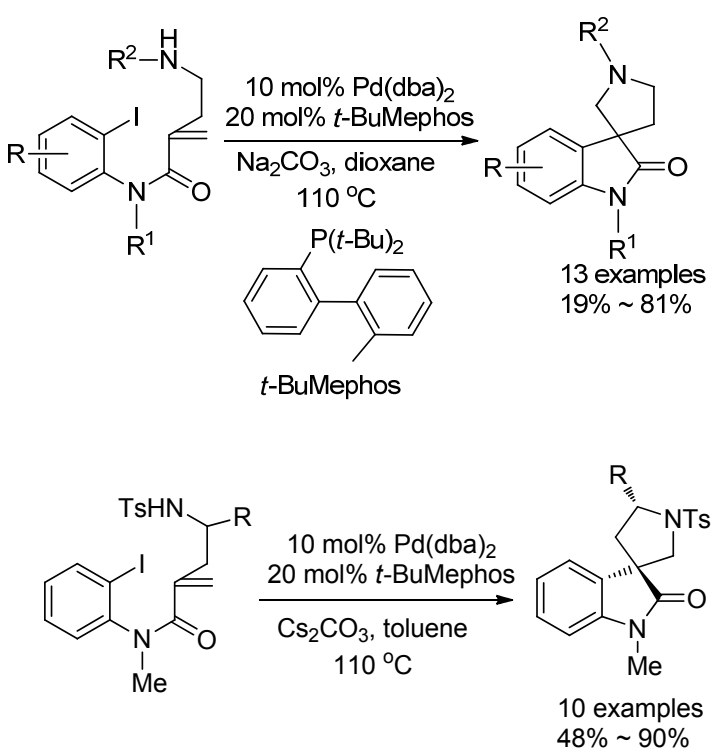

\section{5 环化/羰基化反应}

2010 年, Somfai-Ludlow 等 ${ }^{[42]}$ 报道了钯催化环化/羰 基甲氧基化的反应(Scheme 6). 作者发现，当氮原子上 没有取代基时，反应不发生，这是因为芳基碘优先发生 羰基甲氧基化形成酯，抑制了环化过程；当含有大体积 取代基时，由于空间位阻的作用抑制了上述副反应，从 而促进环化反应的顺利进行. 值得一提的是，尽管先前 已有类似的反应，但是通过控制 $\mathrm{CO}$ 压力、溶剂等因素 而选择性地合成具有非对映选择性的例子鲜有报道.

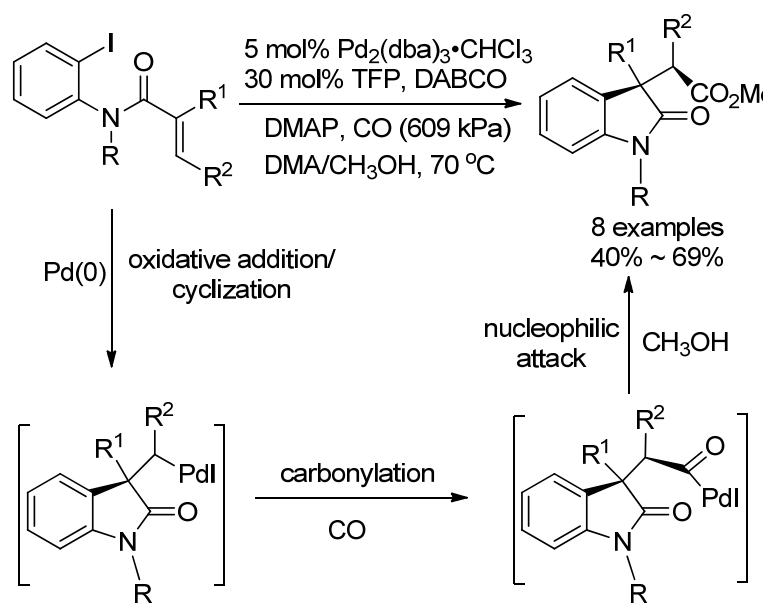

图式 6 环化/羰基化串联反应

Scheme 6 Tandem cyclization/carbonylation

Sridharan 小组 ${ }^{[36]}$ 使用 $\mathrm{Cu} / \mathrm{Pd}$ 双金属催化的环化/ Suzuki 偶联取得很好的效果(Scheme 3), 随后也进行了 环化/羰基胺化反应研究, 得到中等收率的酰胺类衍生 物(Scheme 7).

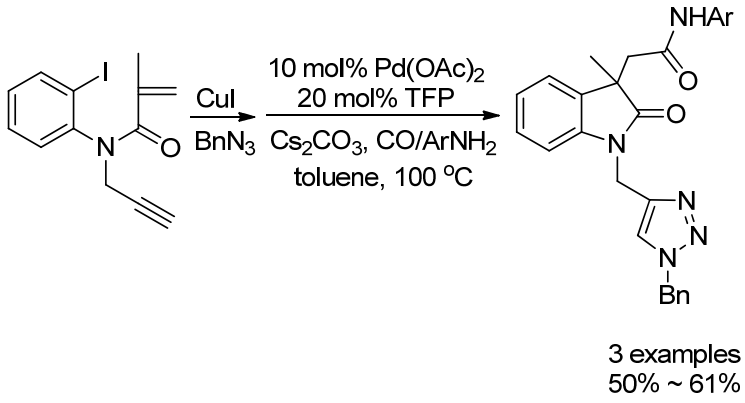

图式 7 铜/钯双金属催化的串联反应

Scheme $7 \mathrm{Cu} / \mathrm{Pd}$ bimetal-catalyzed reaction

2015 年，顾振华小组 ${ }^{[43]}$ 报道了以氯仿作为羰基前 体合成羧酸的反应(Eq. 12). 氯仿在强碱作用下脱去 $\mathrm{HCl}$ ，形成二氯卡宾，该中间体然后再与环化后形成的 烷基钯复合物还原消除，最后氯代物经水解得到羧酸衍 生物，最高产率可达 $98 \%$. 用 $\mathrm{CHCl}_{3}$ 代替 $\mathrm{CO}$ 进行羰基 化反应更加安全，且易操作. 


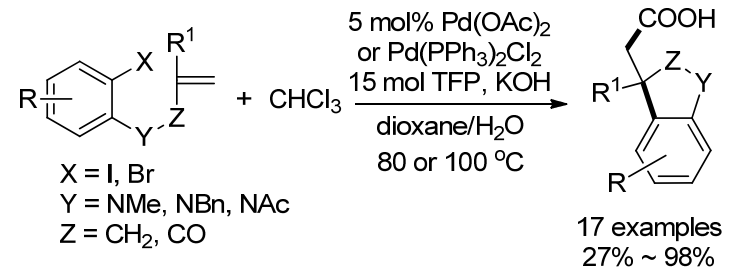

\section{6 环化/C一H 活化}

2009 年, Fagnou 小组 ${ }^{[44]}$ 首次报道了噻吩 $\alpha$ 位的 C$\mathrm{H}$ 活化研究 (Scheme 8). 溴代物环化后形成的钯复合物 可直接活化噻吩 $\alpha$ 位的 $\mathrm{C}-\mathrm{H}$ 键, 通过还原消除构建 $\mathrm{C}\left(\mathrm{sp}^{3}\right)-\mathrm{C}\left(\mathrm{sp}^{2}\right)$ 键. 反应体系中生成的特戊酸盐会促进 噻吩 $\alpha$ 位 $\mathrm{C}\left(\mathrm{sp}^{2}\right)-\mathrm{H}$ 的活化，从而可提高反应的产率.

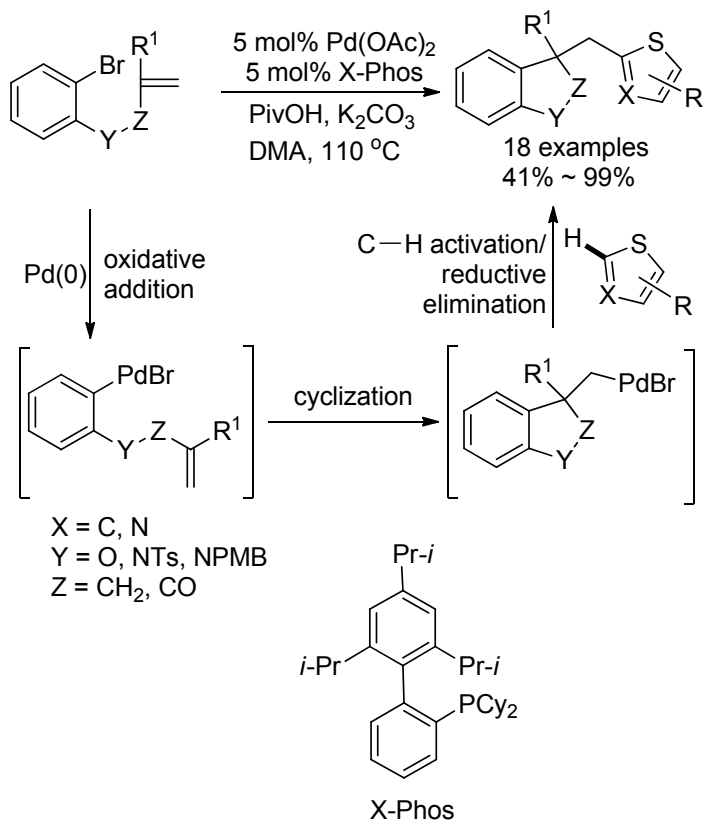

图式 8 环化/C-H 活化串联反应

Scheme 8 Tandem cyclization/C-H activation

2008 年, Kim 小组 ${ }^{[45]}$ 报道了钯催化分子内环化/C$\mathrm{H}$ 活化构建 $3 / 5$ 并环的方法(Eq. 13). 底物首先环化得到 烷基钯物种, 由于缺乏 $\beta$ - $\mathrm{H}$, 该物种不能进行消除, 而 是直接活化氧 $\alpha$ 位 $\mathrm{C}\left(\mathrm{sp}^{3}\right)-\mathrm{H}$ 键, 最后形成具环丙烷骨 架的苯并二氢呋喃衍生物.

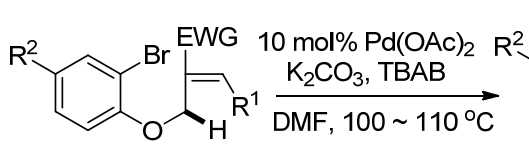

$\mathrm{EWG}=\mathrm{COOMe}, \mathrm{COOEt}$

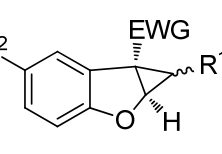

6 examples $39 \% \sim 77 \%$
2008 年, Ruck 等 ${ }^{[46]}$ 报道了涉及活化芳基 $\mathrm{C}$ - $\mathrm{H}$ 键合 成螺环衍生物的研究(Eq. 14). 钯催化澳代烯酰胺发生 分子内的环化, 紧接着对另一个苯环 $\mathrm{C}-\mathrm{H}$ 键活化, 同
时环化完成螺环的构建.

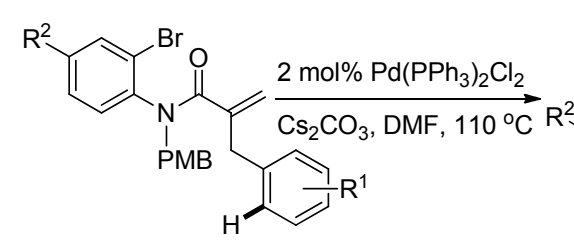

$=0$

9 examples $64 \% \sim 91 \%$
2012 年, 祝介平小组 ${ }^{[47]}$ 通过底物的设计实现了钯 催化另一种串联反应合成螺环化合物的方法(Eq. 15). 与祝介平小组(Eq. 14)不同之处在于活化位点, Ruck 小 组活化的是 $\mathrm{C}\left(\mathrm{sp}^{2}\right)-\mathrm{H}$, 而祝介平小组活化的是 $\mathrm{C}\left(\mathrm{sp}^{3}\right)$ $\mathrm{H}$. 同年, 祝介平小组 ${ }^{[48]}$ 在此基础上又报道类似反应 (Eq. 16). 但反应启动顺序相反, 并且对卤代物及拟卤代 物有一定限制, 当 $\mathrm{X}=\mathrm{Cl}$ 或 OTf 时, 反应不能发生.
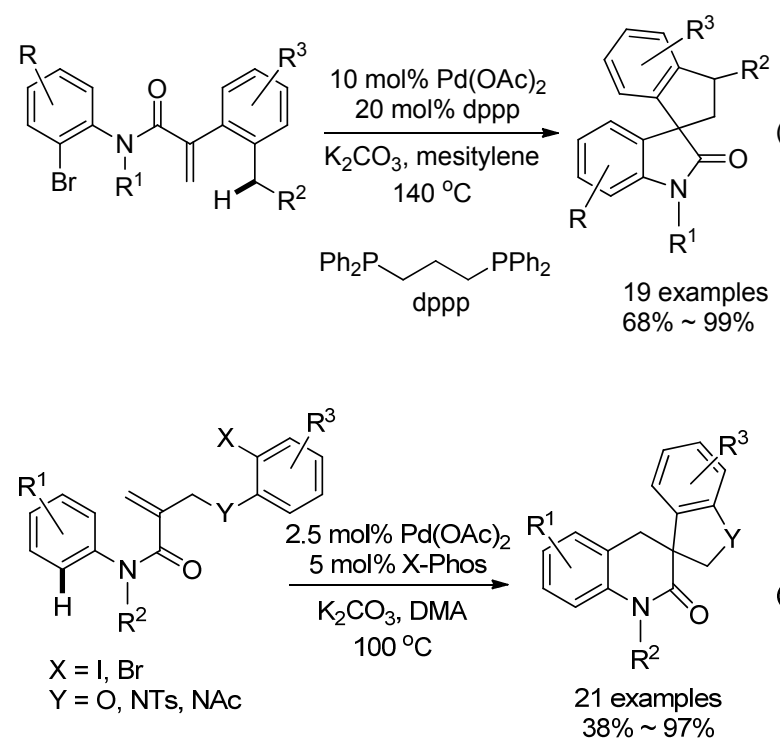

接着，祝介平小组 ${ }^{[49]}$ 运用类似方法又报道了四并 环化合物的合成，该方法涉及钯迁移(Scheme 9). 底物 环化形成的烷基钯经过 1,4-迁移得到芳基钯物种，最后 再通过活化苯亚甲基上 $\mathrm{C}\left(\mathrm{sp}^{3}\right)-\mathrm{H}$ 键还原消除而成四环 化合物. 2015 年, 该小组 ${ }^{[50]}$ 再对该类反应进行了研究, 将底物中苯环的 $\alpha$ 位碳去掉, 直接实现了芳基 $\mathrm{C}-\mathrm{H}$ 键 的活化(Eq. 17). 这一系列反应都具有很好的底物适应 性及高收率等优点, 但酰胺中氮原子上需要有取代基来 抑制副反应的发生.

2015 年, 李瑞祥小组 ${ }^{[51]}$ 首次报道纳米级钯催化分 子间串联反应, 得到苯并二氢呋喃二聚体的研究 (Scheme 10). 反应可能机理是钯催化溴代物环化形成 


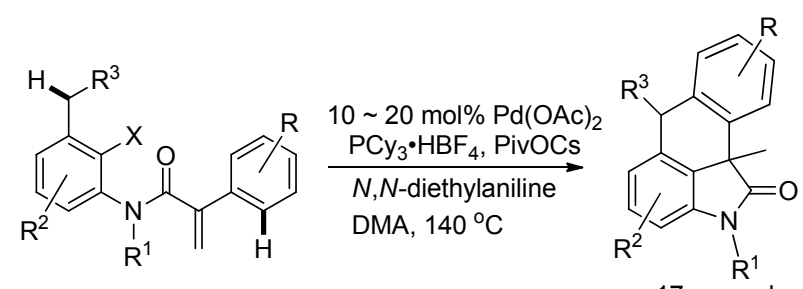

$\mathrm{X}=\mathrm{I}, \mathrm{Br}, \mathrm{Cl}$

$\operatorname{Pd}(0) \mid \begin{gathered}\text { oxidation addition/ } \\ \text { cyclization } \\ \mathrm{R}\end{gathered}$

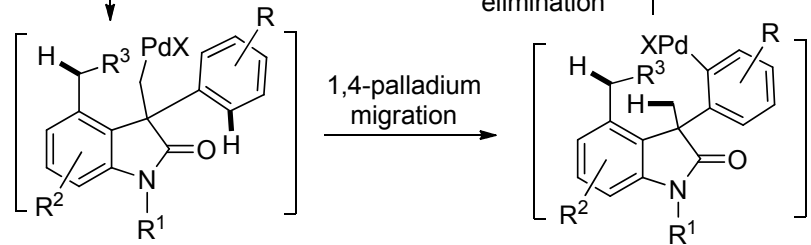

图式 9 环化/钯迁移/C-H 活化串联反应

Scheme 9 Tandem cyclization/Pd-migration/C- $-\mathrm{H}$ activation

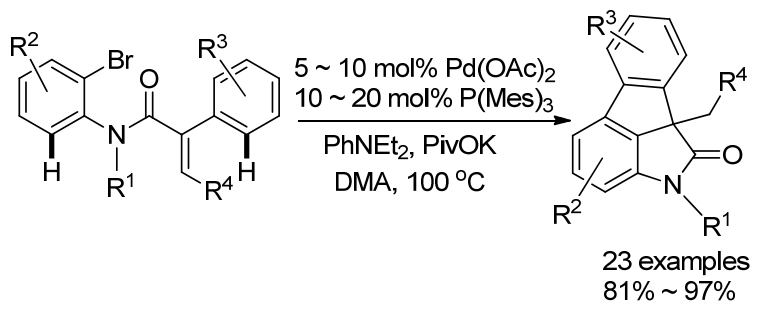

烷基钯，该物种可被还原; 接着钯物种直接活化还原产 物的 $\mathrm{C}\left(\mathrm{sp}^{3}\right)-\mathrm{H}$, 最后还原消除得到二聚体. 正如之前 提到, 季铵盐四正丁基澳化铵(TBAB)提高了反应的产 率. 反应不仅适用于自身的偶联, 还可以适用于不同分 子间的偶联. 这是首例发现钯活化分子间 $\mathrm{C}\left(\mathrm{sp}^{3}\right)-\mathrm{H}$ 形 成二聚的反应, 为今后的研究提供了重要参考价值.

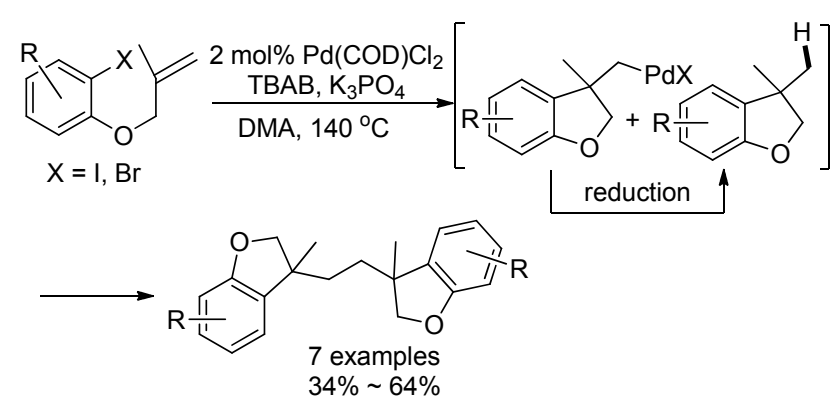

图式 10 吕联的环化/二聚化反应

Scheme 10 Tandem cyclization/dimerization

\section{7 环化/其他偶联}

2007 年, 祝介平小组 ${ }^{[2]}$ 报道了钯作用下碘代烯酰 胺的串联反应(Scheme 11). 首先钯插入到底物 C-I 中, 紧接着环化产生五元钯复合物, 然后氧基置换钯物种的 硒原子，最后发生还原消除得到氰基吲哚. 产物经过几 步简单的转化便可得到能够抑制乙酰胆碱酶的天然产
物 esermethole 和 physostigmine. 另外，他们也研究了该 反应的不对称版本，当加入手性配体 (S)-Difluorphos, 对映选择性最高为 $72 \%$ ee. 2011 年, Kim 小组 ${ }^{[33]}$ 以 $\mathrm{Pd}(\mathrm{OAc})_{2} / \mathrm{TBAC} / \mathrm{Na}_{2} \mathrm{CO}_{3}$ 作为最佳反应条件，将该方法 扩展到了氰基苯并二氢呋喃的合成.

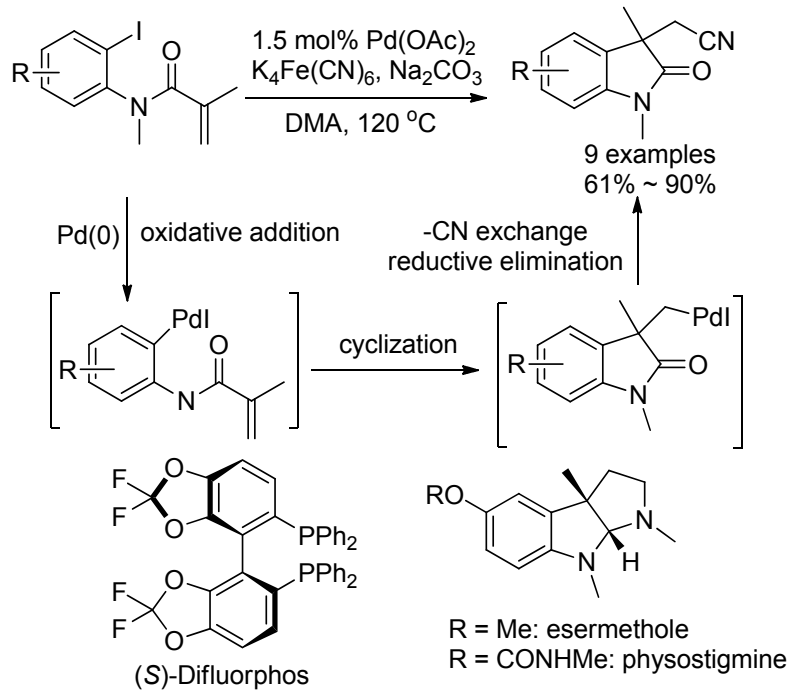

图式 11 环化/氧基化串联反应

Scheme 11 Tandem cyclization/cyanation

2009 年, Takemoto 小组 ${ }^{[54]}$ 报道氨基甲酰卤与分子 内共轭二烯的分子内反应(Eq. 18). 酰卤环化生成烯丙 基钯，随后它被亲核试剂进攻生成末端取代的产物。除 了外加的亲核试剂以外，还可以被自身脱除的 $\mathrm{Cl}^{-}$进攻. 2011 年，作者 ${ }^{[55]}$ 在原有基础上发展了构建 $\mathrm{C}-\mathrm{Si}$ 键的反 应(Scheme 12). 收率整体有所提高，而且该产物可通过 Sakurai 反应，得到含有多个手性中心的环状化合物。
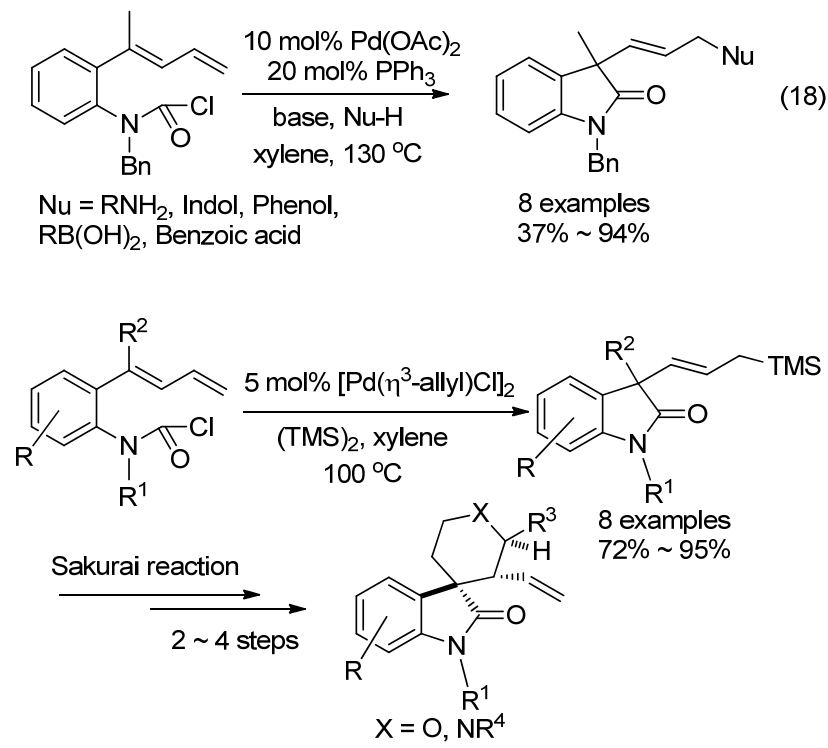

图式 12 环化/形成碳硅键的串联反应

Scheme 12 Tandem cyclization/formation of $\mathrm{C}-\mathrm{Si}$ bond 
2011 年, Lautens 小组 ${ }^{[56]}$ 首次研究了钯催化下, 芳基 碘环化/还原消除得到碘代苯并五元杂环的反应(Eq. 19). 研究表明, 大位阻 Q-phos 配体起着决定性作用, 它能够 加速烷基钯复合物还原消除形成 $\mathrm{C}-\mathrm{I}$ 键. 该方法避免 了传统方法中对卤素的浪费, 符合绿色化学的原则, 且 产率均能达到 $92 \%$ 以上. 但是该方法仅限于芳基碘化合 物，芳基溴、氯不能进行类似反应.

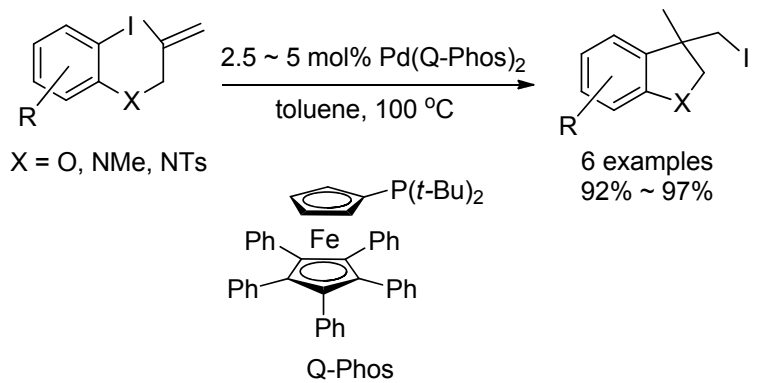

2013 年, 顾振华小组 ${ }^{[57]}$ 研究了钯催化下芳基卤化 物与对甲苯磺酰腙的串联反应(Eq. 20). 芳基卤代物在 钯作用下首先环化得到烷基钯, 它能够与对甲苯磺酰腙 形成的卡宾顺利进行偶联形成烯基吲哚. 延长酰胺烷基 链的长度可以得到更复杂的螺环化合物, 该方法为合成 复杂的吲哚烯烃提供了一种新的方法.

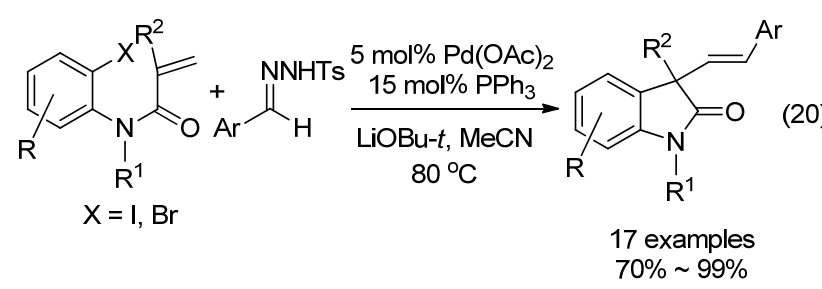

\section{$1.8 \mathrm{C}-\mathrm{H}$ 活化环化/其他偶联}

2009 年, 李金恒小组 ${ }^{[58]}$ 报道了 $\mathrm{C}-\mathrm{H}$ 活 化/烯基钯 还原的方法(Scheme 13). 首先 $\operatorname{Pd}(\mathrm{OAc})_{2}$ 对炔酰胺的苯 环进行 $\mathrm{C}-\mathrm{H}$ 活化, 接着再与炔配位、加成得到烯基钯, 随后该物种被氢还原形成产物. 作者也提出了另一种反 应机理则, 先对炔的氢钯化反应, 随后活化 $\mathrm{C}-\mathrm{H}$ 及还 原消除得到五元环. 该反应受热力学控制, 化合物的构 型可以通过调控温度而得到. 当温度为 $80{ }^{\circ} \mathrm{C}$ 时, $(Z)$-产 物为主; 温度为 $140{ }^{\circ} \mathrm{C}$ 时, $(E)$-产物为主.

2010 年, 祝介平小组 ${ }^{[59]}$ 研究了钯催化不饱和烯酰 胺的反应(Eqs. 21 和 22). 首先钯活化烯酰胺邻位的 C$\mathrm{H}$ 键, 随后环化得到钯复合物, 最后该物种发生乙酰氧 基化形成 $\mathrm{C}-\mathrm{O}$ 键或发生分子内的胺化反应形成 $\mathrm{C}-\mathrm{N}$ 键. 当使用不同催化剂及溶剂, 则得到不同的产物. $\mathrm{Pd}(\mathrm{OAc})_{2} / \mathrm{AcOH}$ 体系主要发生乙酰氧基化反应, $\mathrm{PdCl}_{2} / \mathrm{MeCN}$ 体系主要发生胺化反应.

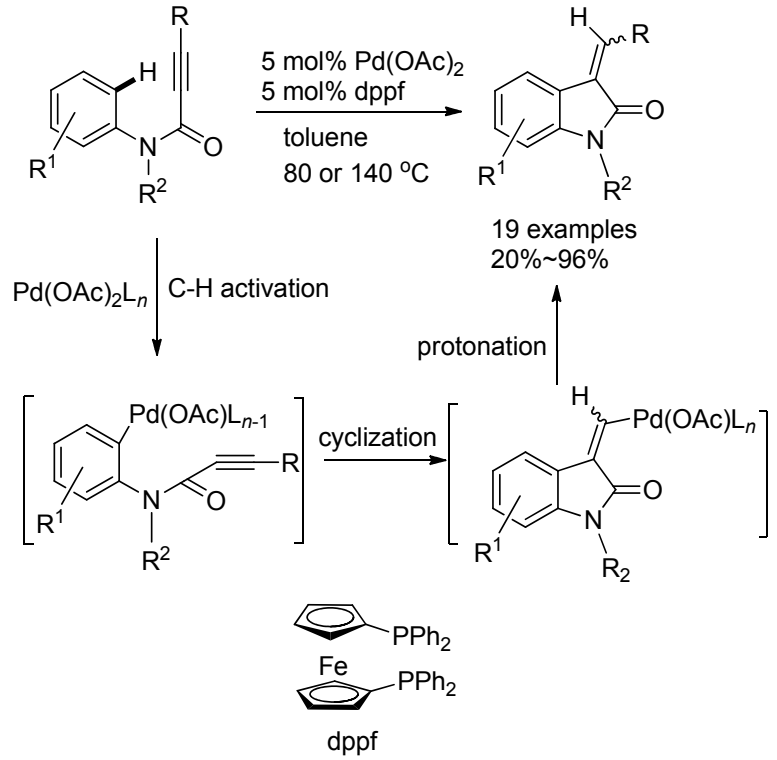

图式 $13 \mathrm{C}-\mathrm{H}$ 活化/环化/质子化串联反应

Scheme 13 Tandem C $-\mathrm{H}$ activation/cyclization/protonation<smiles>[R]CC(=C)C(=O)N([R])c1ccc[R]:[R]1[H]</smiles>

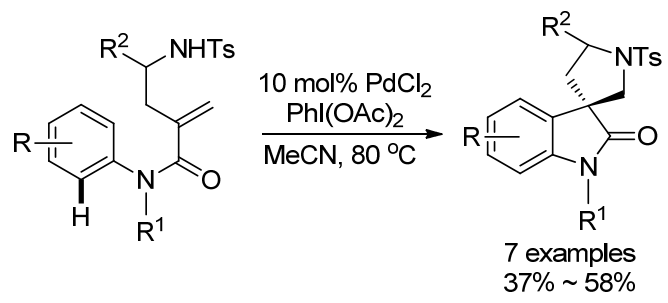

2011 年, 刘国生小组 ${ }^{[60]}$ 报道了腈类化合物的合成. 反应依次对芳基及乙腈中的 $\mathrm{C}-\mathrm{H}$ 键活化而形成两个 $\mathrm{C}-\mathrm{C}$ 键(Eq. 23). 添加剂 $\mathrm{AgF}$ 对 $\mathrm{C}-\mathrm{H}$ 的活化扮演重要 的角色，在扩展这类反应时，乙腈的活性比其它腈类高. 2012 年, 他们 ${ }^{[61]}$ 以相同的起始物，又报道三氟甲基化的 反应(Eq. 24).

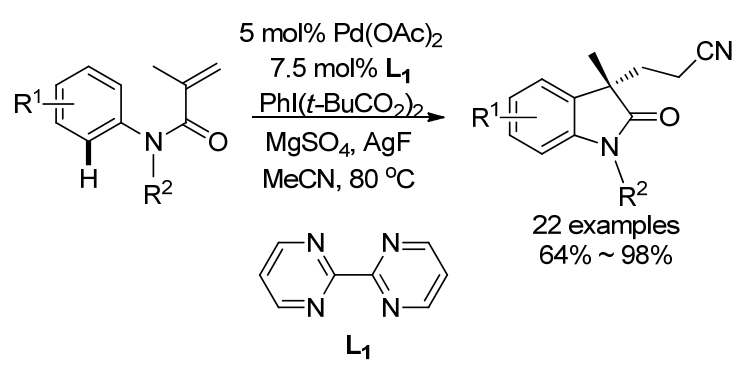




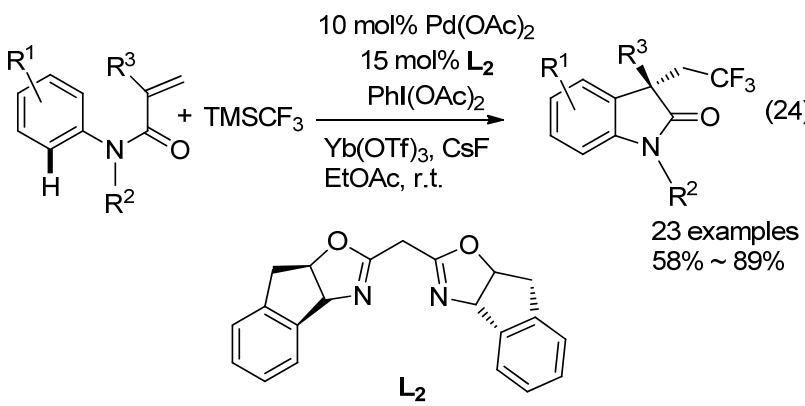

\section{9 异氧酸苯酯的环化/其他偶联}

2005 年, Yamamoto 小组 ${ }^{[62]}$ 报道了钯催化异氧酸苯 酯与末端炔化物的串联反应(Scheme 14). 首先炔在钯 作用下形成钯炔, 随后钯炔与异氧酸苯酯的参键配位, 紧接着碳钯化形成烯基钯, 该物种对异氧酸苯酯中的羰 基亲核进攻，最后还原消除得( $Z$ )-产物，同时可以异构 化形成 $(E)$-产物. 该反应立体选择性好, 以 $(E)$ 式为主要 构型，大部分产物的 $(E) /(Z)$ 比例 $>99 ： 1$.<smiles>[R]Cc1cc([R])c([R])cc1[N+](=O)[O-]</smiles>

图式 14 碳钯化/亲核加成串联反应

Scheme 14 Tandem carbopalldation/nuclephilic reaction

2009 年, Murakami 小组 ${ }^{[63]}$ 用硫醇(Scheme 15)或醇 (Eq. 15)代替末端炔进行了这类反应. 首先钯与异氰酸 苯酯配位, 接着氧化环化后得到烯基钯复合物, 随后醇 置换配体, 最后还原消除和异构化得吲哚的烯炔产物. 同样, $(E)$-产物为主, 多数产物 $(E) /(Z)>90 ： 1$, 反应只 需 $1 \mathrm{~mol} \%$ 催化量便可顺利进行. 同年, 他们又成功地将 这类反应拓展到了胺类化合物的合成 ${ }^{[64]}$.

2010 年, 他们 ${ }^{[65]}$ 进一步研究, 将普通醇换成苯甲醇 (Scheme 16)或烯丙醇(Eq. 26), 使用 CpPd( $\pi$-allyl)/dppf 作 催化体系, 没有得到预期的产物, 却生成 3,3-双取代衍生 物. 这是因为在这类催化体系下, 烯醇式中间体的烯丙 基或苯亚甲基从氧迁移到碳上, 经历 1,3-迁移. 而且增加 烯丙醇的用量时( $>10$ equiv.), 氮原子会被烯丙基化.

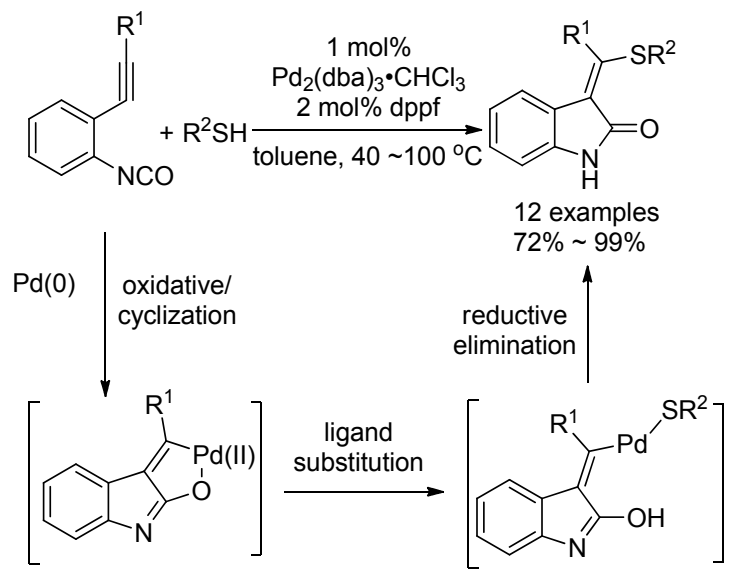

图式 15 环化/着基化串联反应

Scheme 15 Tandem cyclization/hydroxylation
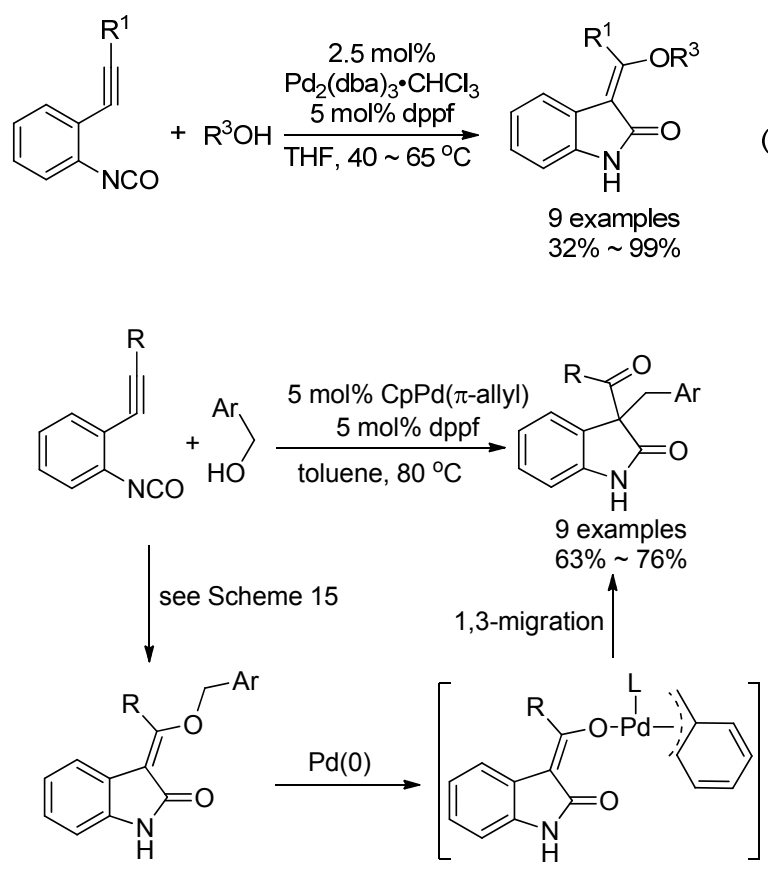

图式 16 环化/着基化/迁移串联反应

Scheme 16 Tandem cyclization/ hydroxylation/migration

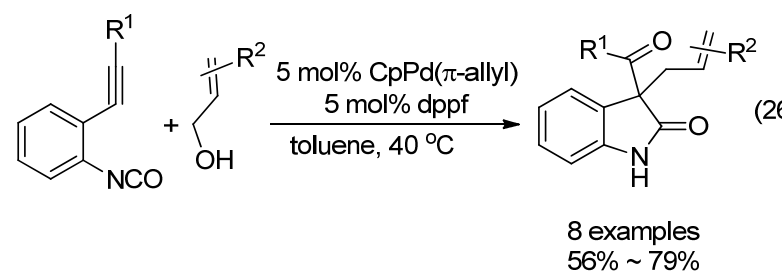

\section{2 钯催化的偶联/环化反应}

2004 年, Wolfe 小组 ${ }^{[66]}$ 报道了钯催化 2-烯丙基苯胺 与芳基溴的反应(Schemes 17 和 18). 钯首先催化芳基溴 与取代苯胺进行 Buchwald-Hartwig 反应形成仲胺，接着 催化另一分子芳基溴与烯基胺发生胺钯化形成 $\mathrm{C}-\mathrm{N}$ 
键, 最后还原消除形成 $\mathrm{C}-\mathrm{C}$ 键. 研究表明, 双齿配体 DPE-phos 的电子效应及空间位阻能有效地避免形成叔 胺，同时也能促进 $\mathrm{C}-\mathrm{N}$ 键的形成及最后的还原消除， 使用不同的芳基溴可得到多种衍生物.

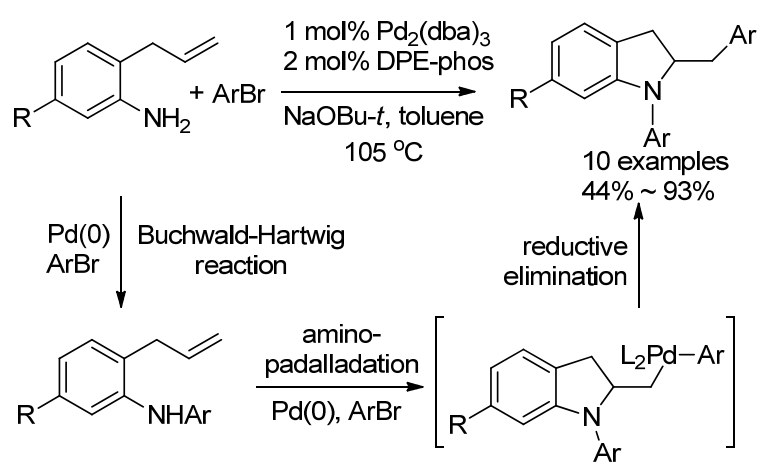

图式 17 Buchwald-Hartwig/胺钯化串联反应 Scheme 17 Tandem Buchwald-Hartwig/aminopadalladation

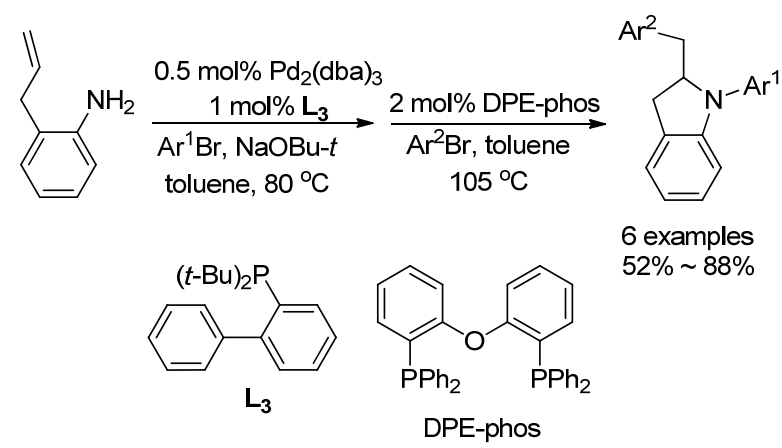

图式 18 Buchwald-Hartwig/胺钯化串联反应

Scheme 18 Tandem Buchwald-Hartwig/aminopadalladation

2010 年, 该小组 ${ }^{[67]}$ 在相同底物的氮上引入烯丙基 进行类似反应，又合成了三环含氮化合物(Eq. 27). 与上 面机理不同在于先形成胺钯化中间体，再形成碳钯化中 间体，最后还原消除得到 6/5/5三环化合物. 该方法具有 高的非对映体选择性, $d r$ 最高可达 $20: 1$, 芳基上能够 容忍三氟甲基、甲氧基、甲基等基团. 当氮上的取代基 为 $o$-烯丙基苯基时, 芳基钯物种在此条件下会经历 1,3钯迁移形成 6/5/5/6 四环化合物(Eq. 28).

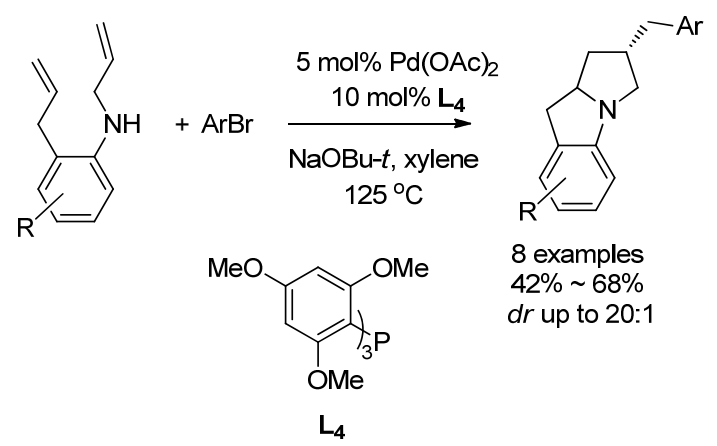

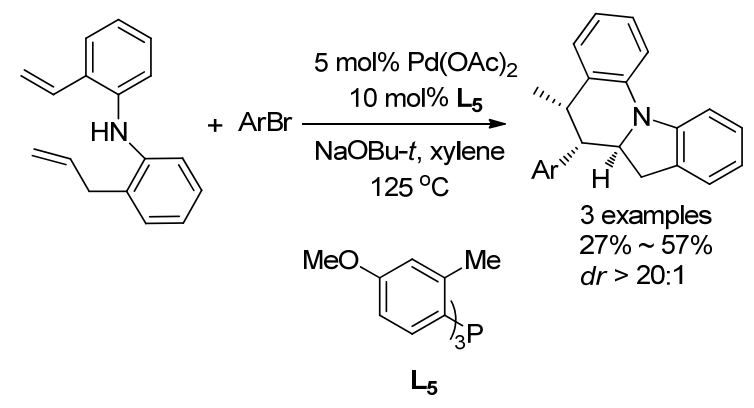

2009 年, Lautens 小组 ${ }^{[68]}$ 以苯胺和降冰片二烯为底 物, $\mathrm{Pd}(\mathrm{OAc})_{2} / \mathrm{P}(t-\mathrm{Bu})_{3} \cdot \mathrm{HBF}_{4} / \mathrm{Cs}_{2} \mathrm{CO}_{3}$ 为催化体系, 执行 碳钯化/胺化反应形成多环化合物(Scheme 19). 产物即 可通过 Diles-Alder 反应得到更复杂的多环化合物; 又可 在低温下经臭氧氧化得到二羟基化合物.

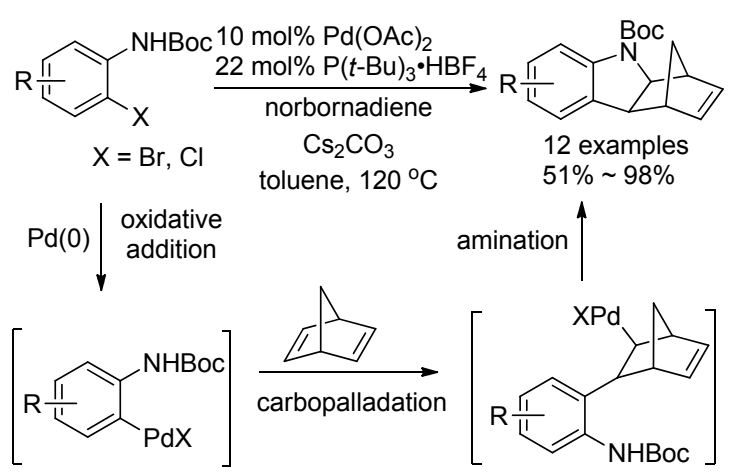

图式 19 碳钯化/胺化串联反应

Scheme 19 Tandem carbopalladation/amination

2011 年, Cacchi 小组 ${ }^{[69]}$ 研究了 Heck/Heck 环化反应 (Scheme 20). 首先在 $\mathrm{Pd}_{2}(\mathrm{dba})_{3}$ 催化下, 苯基重氮四氟硼 酸盐与烯丙基胺的 Heck 反应得到中间体，紧接着加入 $\mathrm{Pd}(\mathrm{OAc})_{2} / \mathrm{P}(o-\mathrm{tol})_{3}$, 再发生分子内的 Heck 环化得到 $(Z)-$ 二氢吲哚产物.

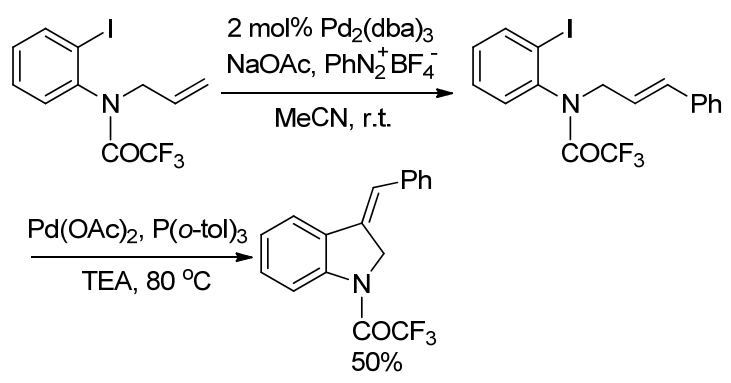

图式 $20 \mathrm{Heck} /$ 还原 Heck 串联反应

Scheme 20 Tandem carbopalladation/amination

2008 年, Booker-Miburm 小组 ${ }^{[70]}$ 研究了取代嫝与共 轭二烯为底物的反应(Scheme 21). 脲的芳基邻位 $\mathrm{C}-\mathrm{H}$ 被活化, 接着与共轭烯烃碳钯化形成 $\mathrm{C}-\mathrm{C}$ 键, 并得到 
烯丙基钯, 随后钯物种发生分子内胺化反应，最后得到 烯基二氢吲哚产物. 芳基中间位有强吸电子基时会抑制 $\mathrm{C}-\mathrm{H}$ 键的活化，从而降低反应的速率及产率.

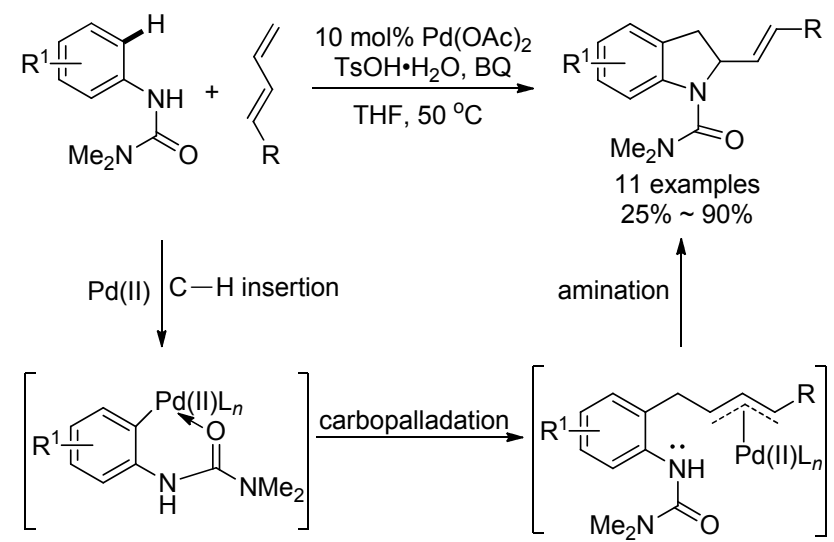

图式 $21 \mathrm{C}-\mathrm{H}$ 插入/碳钯化/胺化串联反应

Scheme 21 Tandem $\mathrm{C}-\mathrm{H}$ insertion/carbopalladation/amination

2015 年, Maiti 小组 ${ }^{[71]}$ 报道了取代苯酚与不饱和烯 酸的反应(Scheme 22, Eq. 29). 邻二氮杂菲(1,10-phen)与 钯的配位增加了钯盐的溶解性与亲电性, 快速活化苯酚 邻位 $\mathrm{C}-\mathrm{H}$ 键, 接着对不饱和烯酸双键的插入, 随后脱 羧、环化得到环状钯物种, 最后 $\beta-\mathrm{H}$ 消除得产物. 值得 一提的是, 在体系中加入 $\mathrm{D}_{2} \mathrm{O}$, 在脱羧得到烯丙基钯后 发生 H/D 交换, 直接形成较高收率的氞代化合物.

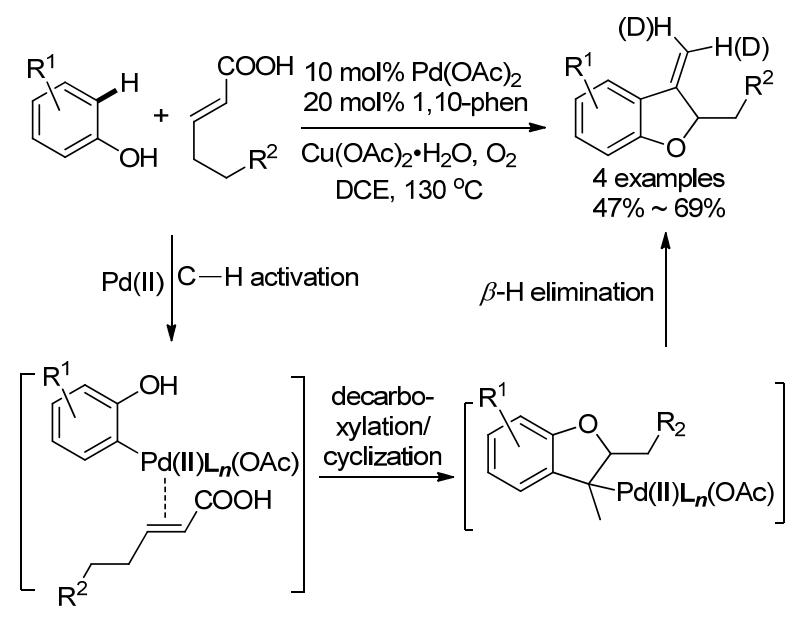

图式 $22 \mathrm{C}-\mathrm{H}$ 活化/脱羧/环化串联反应

Scheme 22 Tandem $\mathrm{C}-\mathrm{H}$ activation/decaoxylation/cyclization

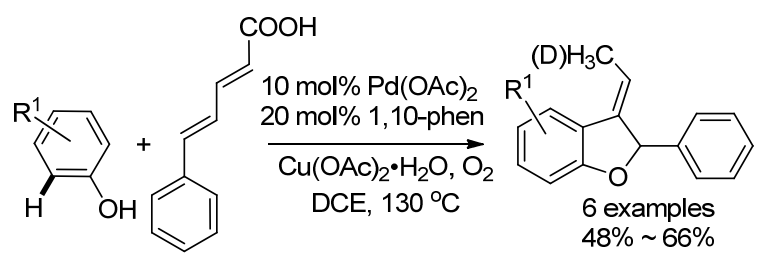

2007 年, 祝介平小组 ${ }^{[72]}$ 使用 $\mathrm{Cu} / \mathrm{Pd}$ 催化三组分构建
二氢吲哚结构 (Scheme 23). 酰胺与炔基进行 Sonogashira 偶联得到内炔，接着另一分子芳基碘被氧 化加成, 形成的钯物种对酰胺炔基的碳钯化反应，最后 活化芳基邻位 $\mathrm{C}-\mathrm{H}$ 键及还原消除形成最终产物.

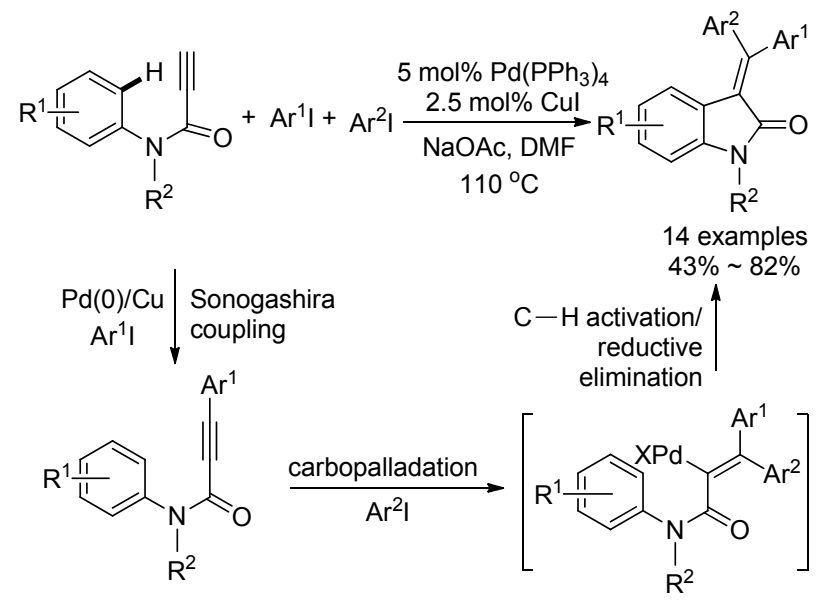

图式 23 Sonogashira 偶联/碳钯化/C-H 活化串联反应 Scheme 23 Tandem Sonogashira coupling/carbopalladation/ $\mathrm{C}-\mathrm{H}$ activation

2008 年，李金恒小组也研究了炔酰胺的反应 (Scheme 24 和 Eq. 30), 但该反应涉及 Pd(II)与 Pd(IV)的 氧化还原. 反应过程包括胺钯化 ${ }^{[73]}$ 或乙酰氧基化 ${ }^{[74]}$ 、 $\mathrm{C}-\mathrm{H}$ 活化及还原消除. 产物以 $(E)$-构型为主, 但随着苯 环上基团位阻的加大，会降低产率.

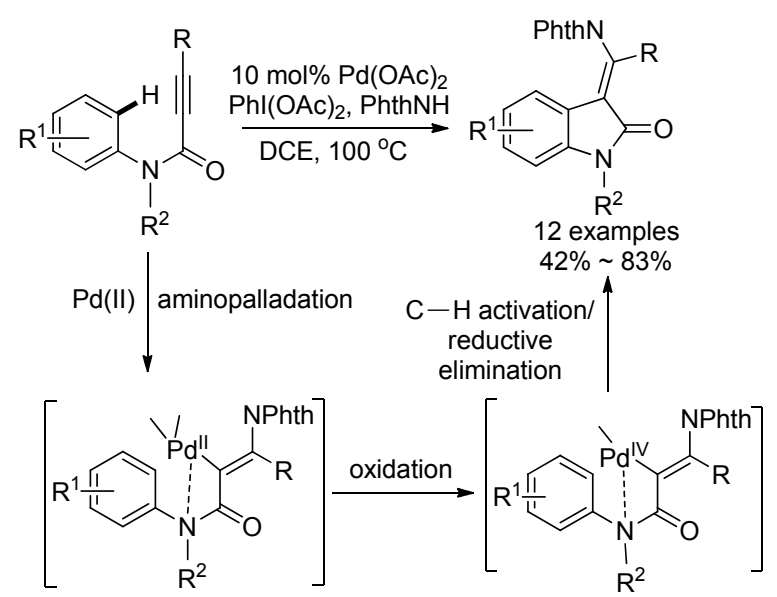

图式 24 胺钯化/碳钯化/C-H 活化串联反应

Scheme 24 Tandem aminopalladation/carbopalladation/C- $-\mathrm{H}$ activation

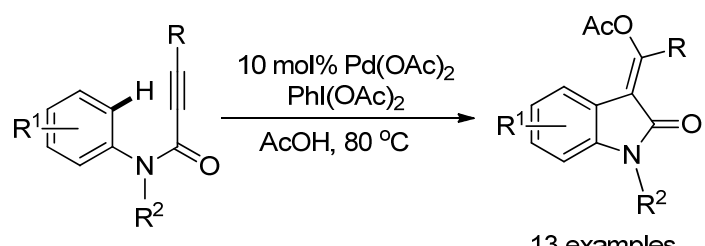
$28 \% \sim 93 \%$ 
2010 年, 潘毅小组 ${ }^{[75]}$ 报道了在空气中进行钯催化合 成二氢吗哚过氧化物的反应(Scheme 25). 反应可能机理 为在钯作用下, 过氧叔丁醇对烯酰胺的双键以自由基方 式氧化加成, 得到过氧中间体, 接着依次活化 $\mathrm{C}\left(\mathrm{sp}^{2}\right)-\mathrm{H}$, $\mathrm{C}\left(\mathrm{sp}^{3}\right)$ - $\mathrm{H}$ 而成环, 形成稳定的双过氧基产物.

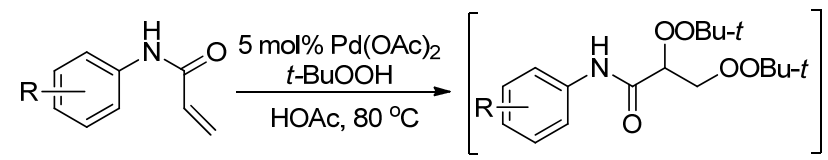

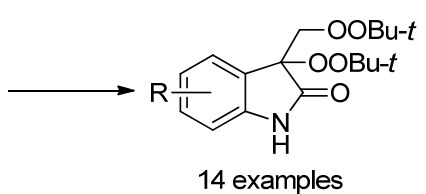

14 examples
$46 \% \sim 96 \%$

图式 25 过氧化/C-H 活化串联反应

Scheme 25 Tandem peroxidation/ $\mathrm{C}-\mathrm{H}$ activation

2014 年, 王细胜小组 ${ }^{[76]}$ 也对钯催化自由基的反应 进行了研究 (Scheme 26). $\mathrm{PhSO}_{2} \mathrm{CF}_{2} \mathrm{I}$ 与钯作用容易形成 二氟甲基自由基, 该自由基对烯酰胺双键的插入形成叔 碳自由基, 接着它对苯环进行自由基取代完成反应.

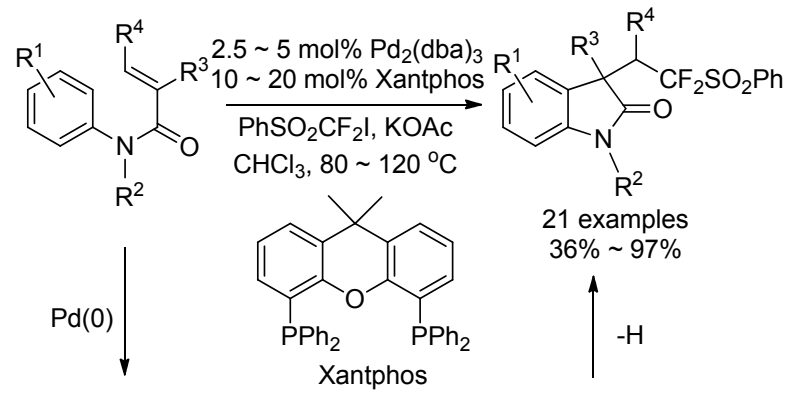

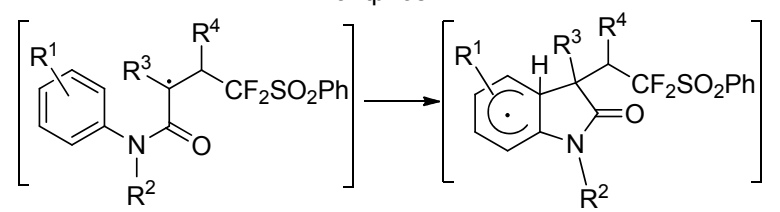

图式 26 自由基环化串联反应

Scheme 26 Tandem radical cyclization

\section{3 钯催化 Wacker 型反应}

Wacker 反应是将烯烃变成醛、酮的有效方法之一, 使用 $\mathrm{CuCl}_{2} / \mathrm{PdCl}_{2}$ 作催化剂, 空气或氧气作氧化剂, 发现 至今一直被广泛应用于有机合成中.

\subsection{Wacker/炔基化反应}

2010 年, Waser 小组 ${ }^{[77]}$ 首次报道了 2-烯基苯酚与有 机高价碘的串联反应(Scheme 27). 钯催化 2-烯基苯酚进 行 Wacker 型环化, 接着被高价碘化物氧化形成四价钯 中间体, 最后还原消除. 与其它钯催化串联反应相比,
该反应实现了 $\mathrm{C}\left(\mathrm{sp}^{3}\right)-\mathrm{C}(\mathrm{sp})$ 键的形成，合成炔基苯并二 氢呋喃.

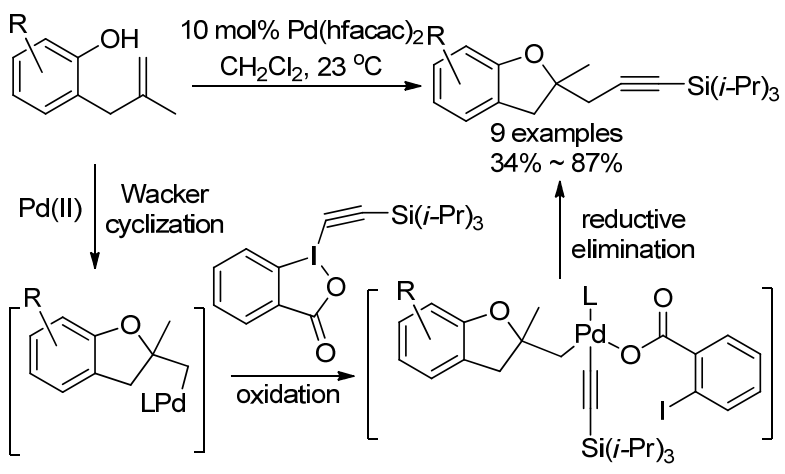

图式 27 Wacker 环化/炔基化串联反应

Scheme 27 Tandem Wacker cyclization/alkynylation

\section{2 aza-Wacker/串联反应}

2006 年, 杨丹小组 ${ }^{[78]}$ 利用吡啶作为配体, 进行了 aza-Wacker 反应研究(Scheme 28). 不饱和酰胺化合物依 次通过胺钯化反应、对双键的插入及 $\beta$-H 消除一步实现 了两个环、一根 $\mathrm{C}-\mathrm{N}$ 键及一根 $\mathrm{C}-\mathrm{C}$ 键的形成. 反应 以 $\mathrm{Pd}(\mathrm{II})$ 来启动反应, 氧气作为氧化剂实现了 $\operatorname{Pd}(0)$ 到 $\operatorname{Pd}(\mathrm{II})$ 的循环.

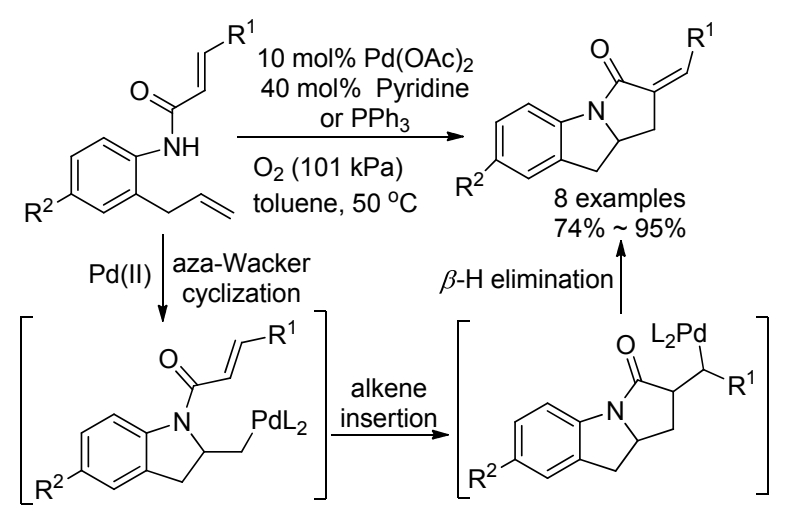

图式 28 aza-Wacker 环化/烯烃插入串联反应

Scheme 28 Tandem aza-Wacker cyclization/alkene insertion

2009 年, 该小组 ${ }^{[79]}$ 进一步研究, 增加了氮原子上取 代基的长度，使用了简单、易得的喹啉或异喹啉作为配 体，经历上述相似历程得到螺环化合物，其非对映选择 性高 $(d r>24: 1)$ (Eq. 31), 另外配体喹啉或异喹啉还能 够抑制烯烃的异构化.

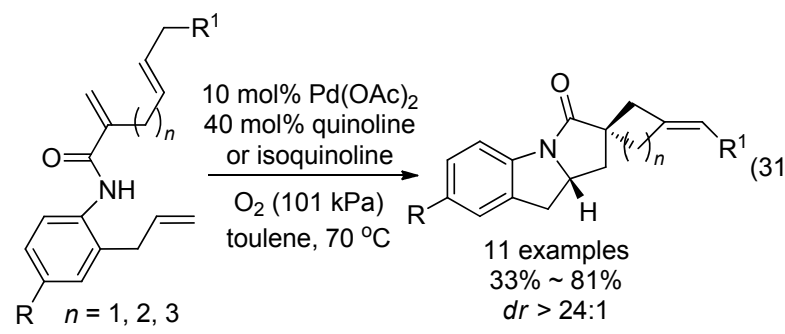


2006 年, 他们 ${ }^{[78]}$ 也研究了不对称催化版本的反应 (Eq. 32), 最后发现使用手性配体(一)-sparteine 及分子 篮, 会得到较高 $e e$ 的产物.

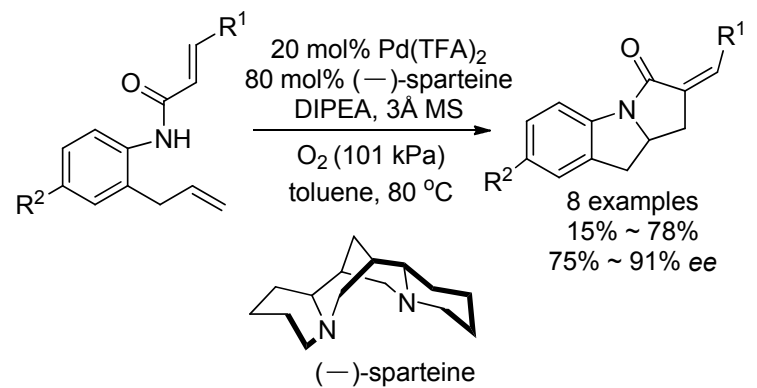

然而，由于 sparteine 配体制备困难，限制了其应用. 2009 年, 她们 ${ }^{[80]}$ 又发展了一种能够在空气中稳定存在 的手性钯催化体系 $\mathrm{Pd}(\mathrm{OAc})_{2} / t-\mathrm{Bu}-\mathrm{QUOX} . \mathrm{R}^{1}$ 无论接吸 电子基还是供电子基都能得到具有更高的对映 $(e e>$ $80 \%)$ 及非对映体选择性 $(d r>24 ： 1)$ 的产物(Eq. 33).

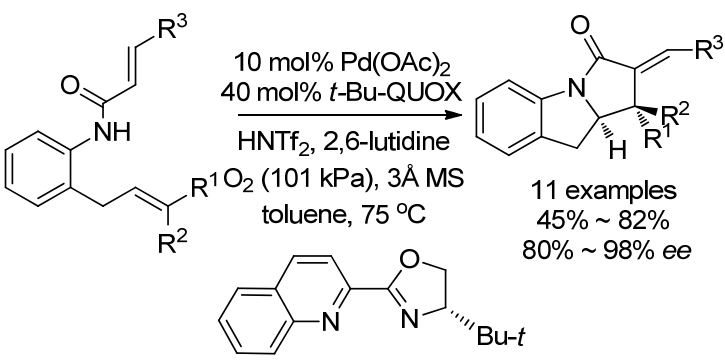

(33)

$t$-Bu-QUOX

2015 年, 该小组 ${ }^{[81]}$ 再次报道烯基胺或酰胺的串联 反应. 反应经过 aza-Wacker 环化/苯亚甲基 $\mathrm{C}\left(\mathrm{sp}^{3}\right)$ - $\mathrm{H}$ 活 化(Eq. 34)或酰胺 $\alpha$ 位 $\mathrm{C}\left(\mathrm{sp}^{3}\right)$ - H 活化(Eq. 35). 虽然特戊 酸有利于活化 $\mathrm{C}\left(\mathrm{sp}^{3}\right)-\mathrm{H}$, 但是不同的催化体系, 会活 化不同位点的 $\mathrm{C}\left(\mathrm{sp}^{3}\right)-\mathrm{H}$. 作者还观察到苯亚甲基

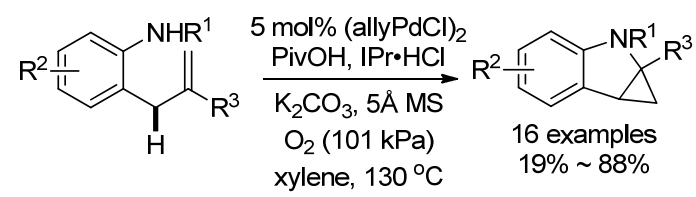<smiles>CCCc1cccc(PC)c1-n1cc[n+](Cc2c(P)cccc2P)c1</smiles>

$\mathrm{IPr} \cdot \mathrm{HCl}$

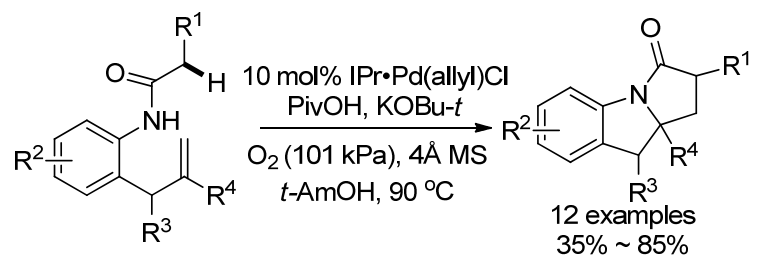

$\mathrm{C}\left(\mathrm{sp}^{3}\right)$ - $\mathrm{H}$ 活化是决速步骤，而酰胺 $\alpha$ 位 $\mathrm{C}\left(\mathrm{sp}^{3}\right)-\mathrm{H}$ 活 化却不是决速步骤.

\section{4 钯催化 Catellani 型反应}

Catellani 反应是以芳基碘代物、碘代脂肪烃、取代 烯烃为原料，加入降冰片烯 (norbornene)在钯催化作用 下，芳基碘代物经过多次邻位的烷基化反应，最后再发 生 Heck 反应，生成多取代的芳烃的反应。该反应牵涉 到 $\operatorname{Pd}(0), \operatorname{Pd}(\mathrm{II}), \operatorname{Pd}(\mathrm{IV})$ 的循环过程，降冰片烯起到了关 键的接力作用.

2006 年, Lautens 小组 ${ }^{[82]}$ 报道钯催化 Catellani 型反 应合成苯并五元杂环化合物的研究(Scheme 29). 首先, $\operatorname{Pd}(0)$ 对芳基卤的氧化加成，接着对降冰烯片的碳钯化 反应，形成的钯物种作为亲电试剂活化芳基中 $\mathrm{C}-\mathrm{H}$ 键, 再次钯化形成钯环，它接着对分子内 $\mathrm{C}-\mathrm{Br}$ 键的插入形 成 $\operatorname{Pd}(\mathrm{IV})$ 物种，该物种通过还原、去碳钯化得到 $\operatorname{Pd}(\mathrm{II})$ 物种，最后再与 $\mathrm{Zn}(\mathrm{CN})_{2}$ 发生 Negishi 偶联得到氧基二氢 吲哚.
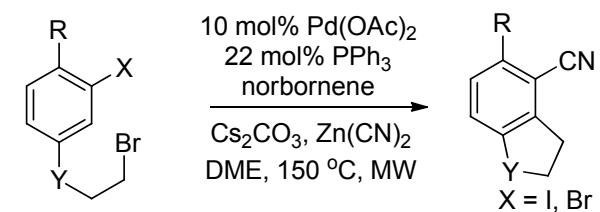

$$
\mathrm{X}=\mathrm{I}, \mathrm{Br}
$$$$
\mathrm{Y}=\mathrm{O}, \mathrm{NTS}
$$
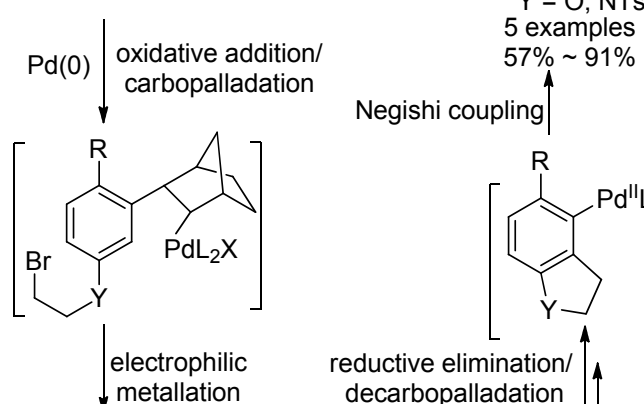

gishicoupling

$\% \sim 91 \%$

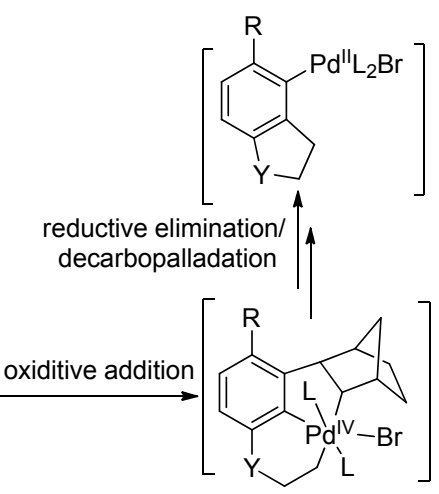

图式 29 Catellani/Negishi 串联反应

Scheme 29 Tandem Catellani/Negishi reaction

2009 年，该小组 ${ }^{[83]}$ 在已有研究基础上作了进一步 探索，又成功地报道了与活泼烯烃的反应(Eq. 36). 在经

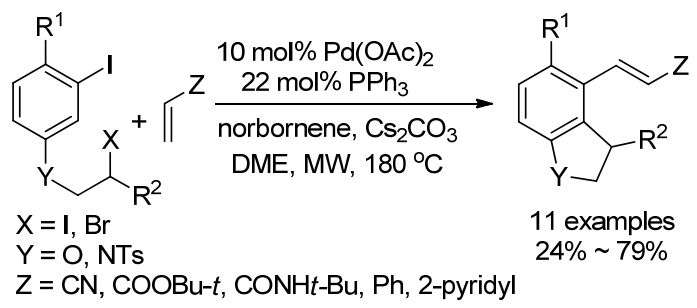


历相似的历程后, 最后一步发生 Heck 反应, 得到苯 并二氢呋喃及二氢吲哚的烯基化合物.

2014 年, 梁永民小组 ${ }^{[84]}$ 以 $\operatorname{Pd}(\mathrm{OAc})_{2}$ 作催化剂, 以 芳基磺酰腙代替 $\mathrm{Zn}(\mathrm{CN})_{2}$, 一步实现了 4-取代烯基的二 氢吲哚的合成(Eq. 37). 反应具有产率高、良好的官能团 兼容性和底物适用广的特点.

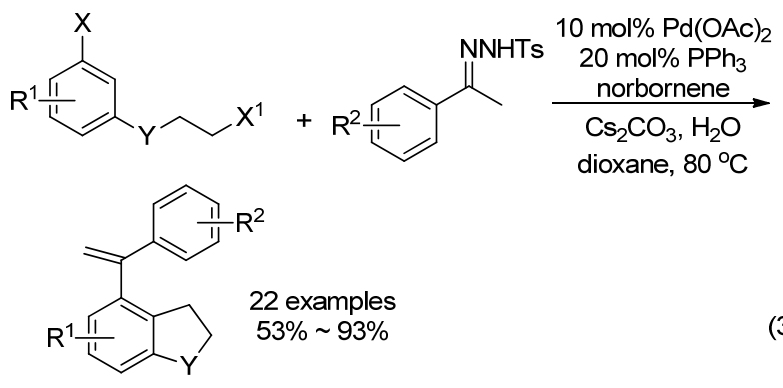

$\mathrm{X}=\mathrm{I}, \mathrm{Br} ; \mathrm{X}^{1}=\mathrm{I}, \mathrm{Br} ; \mathrm{Y}=\mathrm{O}, \mathrm{NT} s$

2007 年, Lautens 小组 ${ }^{[85]}$ 又以取代碘苯和仲胺为底 物, 报道钯催化 Catellani 型反应, 反应经过连续 $\mathrm{C}-\mathrm{C}$ 键和 C-N 键的形成(Eq. 38). 与上面不同在于(Scheme 29), 该反应是由分子间的溴代物进攻形成 $\operatorname{Pd}(\mathrm{IV})$ 物种, 最后发生胺化反应并关环. 选择合适的 $N$-取代基可避 免直接发生 Buchwald-Hartwig 偶联形成叔胺.

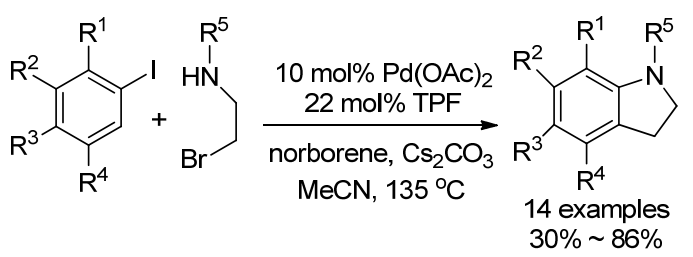

\section{5 其他反应}

2007 年, Muñiz ${ }^{[86]}$ 报道钯催化烯基二胺分子内合成 二氢吲哚二聚体 (Scheme 30). 首先二价钯催化仲胺以 不利的 5-endo-trig 方式成环, 接着二价钯物种被二醋酸 碘苯氧化成烷基四价钯, 最后还原去钯化形成第二根 $\mathrm{C}-\mathrm{N}$ 键, 同时构筑第二个吡咯环. 该二聚体可进一步 用于磺胺类药物的合成.

离子液体作为一种绿色环保型溶剂, 可有效地稳定 过渡金属催化剂, 促进反应的进行, 是常规有机溶剂理 想的替代品 ${ }^{[87]} .2009$ 年, Radhakrishnan 小组 ${ }^{[88]}$ 使用离子 液体 1-丁基-3-甲基咪唑六氟磷酸盐( $\left(\mathrm{bmim}-\mathrm{PF}_{6}\right.$ )作为溶 剂, 邻碘苯酚和桥环肼在钯催化下发生碳钯化作用, 钯 复合物与氧配位并断裂 $\mathrm{C}-\mathrm{N}$ 键打开桥环, 最后通过 $\beta-\mathrm{H}$ 消除非对映选择性得到三环化合物(Scheme 31). 稳 定剂 TBAC 不可缺少, 而当加入三苯基膦配体, 却不能 发生氧钯化反应，而是直接被还原得到取代苯酚.

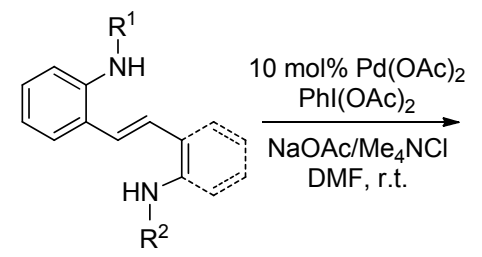<smiles>[R]N1c2ccccc2C2c3ccccc3N([R])C21</smiles>

10 examples $77 \% \sim 93 \%$

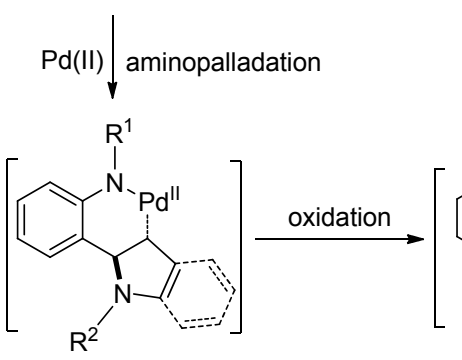
reductive
depallation<smiles>[R20]C1c2ccccc2N([R2])C1c1ccccc1N</smiles>

图式 30 胺钯化/去钯化串联反应

Scheme 30 Tandem aminopalladation/depalladation

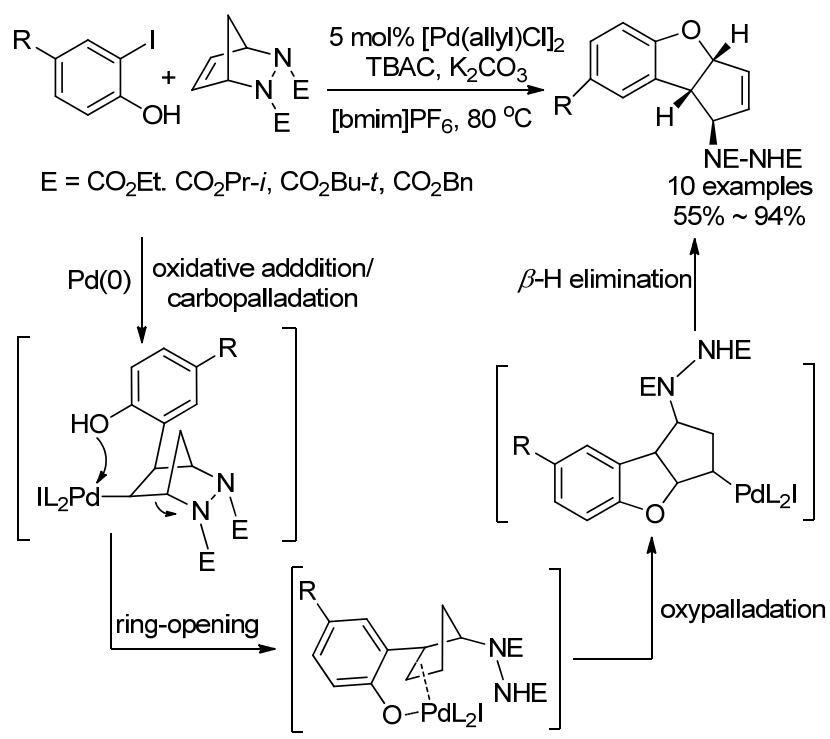

图式 31 碳钯化/氧钯化串联反应

Scheme 31 Tandem carbopalladation/oxypalladation

2013 年, 该小组 ${ }^{[89]}$ 进行了更深入研究, 当桥环肼的 桥头碳换成环丙基时，在相似的反应条件下合成四环骨 架的苯并二氢呋喃衍生物(Scheme 32). 与上述反应不 同, $\beta$ - $\mathrm{H}$ 消除时环丙烷结构被打开，消除得到共轭二烯 中间体，随后该中间体发生氢钯化反应形成 $\pi$-烯丙基 钯，最后发生分子内的亲核取代反应。

同年，该小组 ${ }^{[00]}$ 又将桥环肼的桥头碳换成烯基，以 邻碘苯胺为起始物, 路易斯酸和钯共同作催化剂 (Scheme 33). 首先路易斯酸催化促进苯胺对环肼的 C$\mathrm{N}$ 键亲核进攻, 同时打开环形成二级胺，接着 $\mathrm{Pd}(0)$ 对二 级胺中 $\mathrm{C}-\mathrm{I}$ 的氧化加成, 随后立即对双键的插入形成 烯丙基钯中间体，最后由亲核试剂进攻. 这类方法非对 映选择性好，一步能产生多个手性中心的分子. 


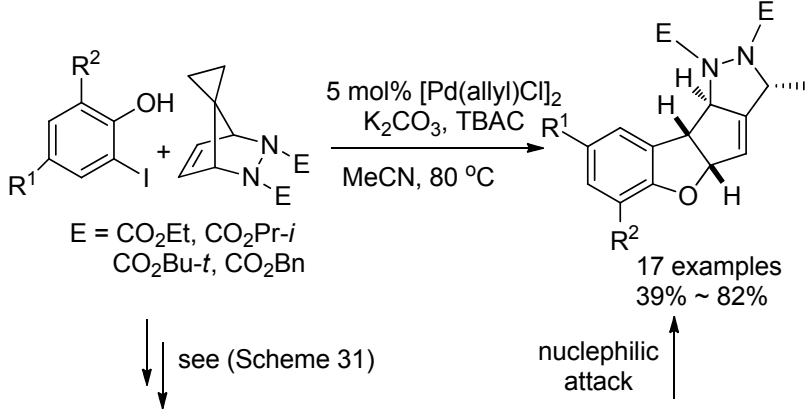

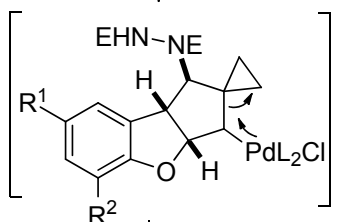

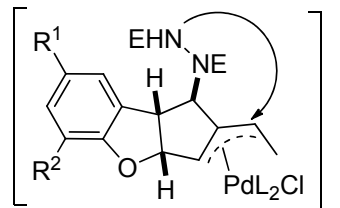

ring-opening of cyclopropane

hydropalladation $\uparrow$

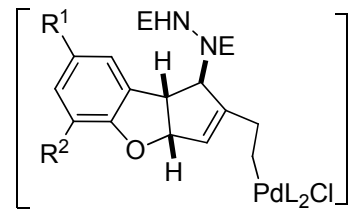

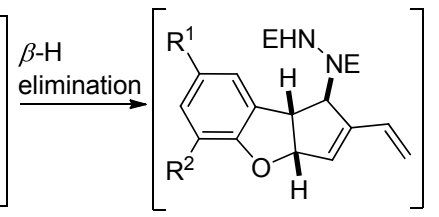

图式 32 环丙烷开环/氢钯化/亲核取代的串联反应

Scheme 32 Tandem ring-opening of cyclopropane/hydro- palladation/nuclephilic subsitution
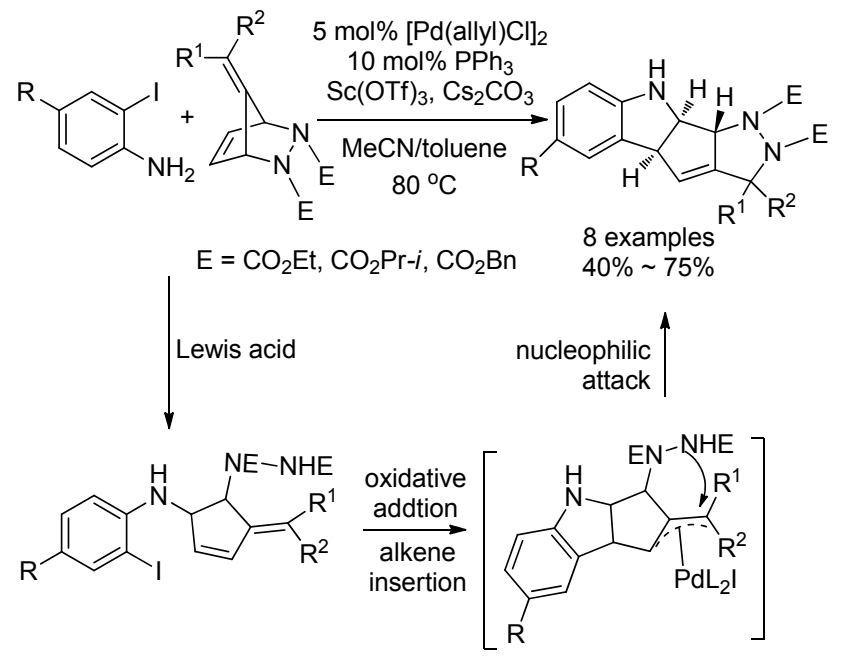

图式 33 路易斯酸及钯催化的串联反应

Scheme 33 Lewis acid and Pd catalyzed reaction

2013 年, 史一安小组 ${ }^{[91]}$ 报道钯催化 $\alpha$-甲基苯乙烯 和二叔丁基环状脲得到螺环化合物的反应(Scheme 34). $\operatorname{Pd}(0)$ 插入到二叔丁基环状脲 $\mathrm{N}-\mathrm{N}$ 键中, 形成四元环, 接着它与 $\alpha$-甲基苯乙烯的双键配位, 然后接受烯丙位的 氢后立即还原消除; 钯再次插入到另一分子二叔丁基环 状脲中 $\mathrm{N}-\mathrm{N}$ 键, 然后由第一分子脲上氮原子进攻成环, 该中间体随后活化邻位 $\mathrm{C}-\mathrm{H}$ 键并释放一分子脲; 第三 分子二叔丁基环状嫝的 $\mathrm{N}-\mathrm{N}$ 被插入形成四价钯物种,
通过脱去叔丁基异氰酸酯得到含钯的乃春中间体，它经 历两次还原消除得到最终产物. 该反应一次可形成两个 环和四根 $\mathrm{C}-\mathrm{N}$ 键，具有底物适应广、反应条件温和等 优点.
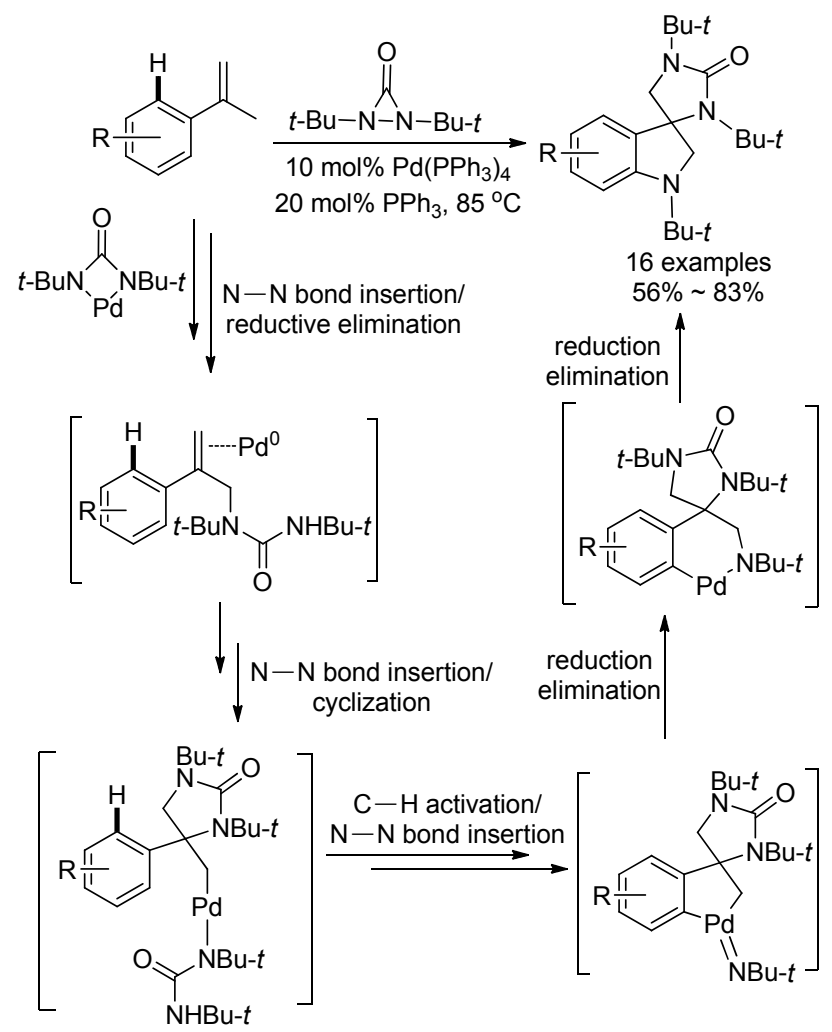

图式 34 芳基及烯丙基 $\mathrm{C}-\mathrm{H}$ 活化的串联反应

Scheme 34 Tandem allylic and aromatic $\mathrm{C}-\mathrm{H}$ activation

随后，他们 ${ }^{[92]}$ 以取代碘苯、二叔丁基环状脲和降冰 片烯为底物进行了类似研究. 在 $\mathrm{Pd}\left(\mathrm{PPh}_{3}\right)_{4} / \mathrm{Cs}_{2} \mathrm{CO}_{3}$ 的催 化体系下，碘苯氧化加成后立即发生碳钯化，接着它活 化芳基中 $\mathrm{C}-\mathrm{H}$ 键形成五元环钯物种, 最后钯物种插入 到二叔丁环状脲的 $\mathrm{N}-\mathrm{N}$ 键中，随后经历相似历程非对 映选择性地形成多环化合物(Scheme 35). 用降冰片二

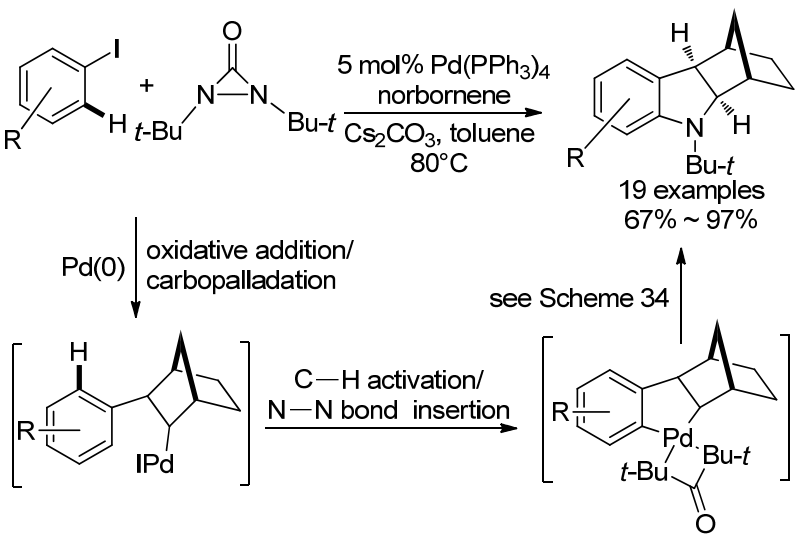

图式 35 碳钯化/C-H 活化/胺化的串联反应

Scheme 35 Tandem carbopalladation/C $-\mathrm{H}$ activation/amination 
烯代替降冰片烯, 也适用于该反应, 而且还研究了分 子内的反应.

2014 年, Anderson 小组 ${ }^{[93]}$ 报道了合成三环类二氢吲 哚的方法(Scheme 36). 链状的二炔胺在钯的催化作用 下经连续碳钯化反应, 再以 $\beta-\mathrm{H}$ 消除同时构建 5/6/5 并 环体系.

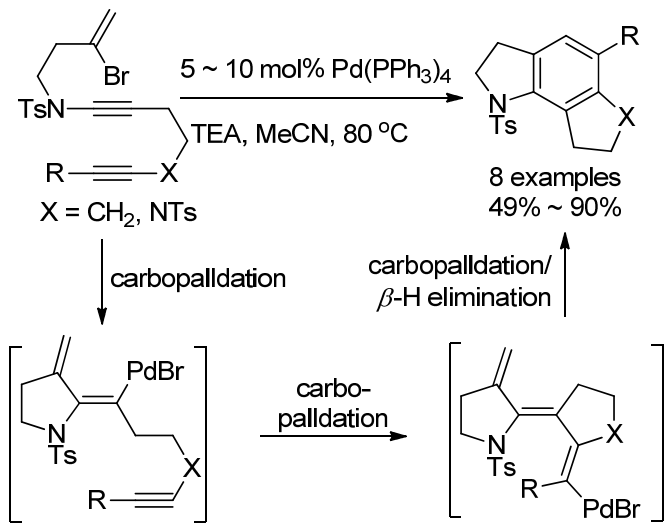

图式 36 连续的碳钯化反应

Scheme 36 Consecutive carbopalladation

2015 年, Wang 等 ${ }^{[94]}$ 对邻碘苯胺与异腈在钯催化下 进行了深入研究 (Scheme 37). 异腈先后两次插入到邻 碘苯胺中, 随后胺化关环, 接着还原消除得到类似于席 夫碱的钯环, 最后它经酸水解得到取代靛红. 该方法反 应试剂简单、易得, 反应条件温和, 且不需要含膦配体.

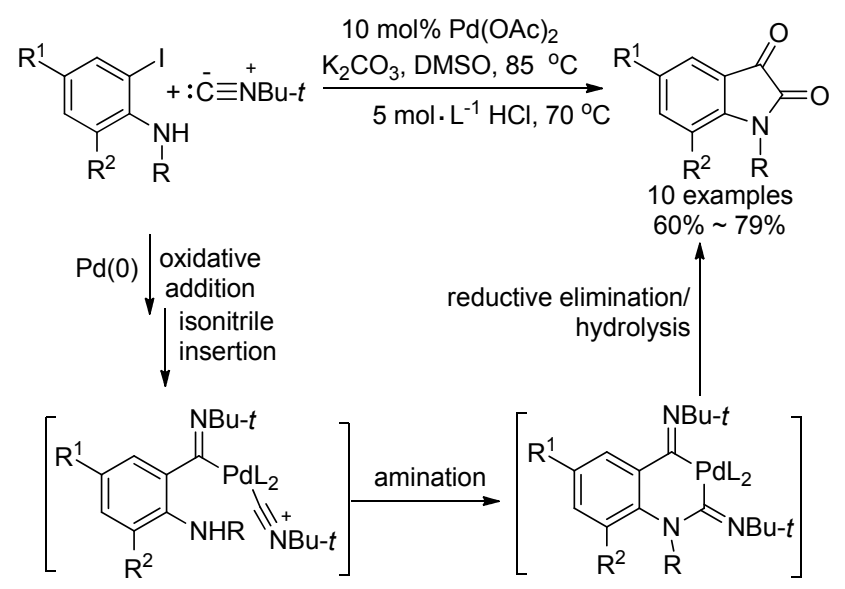

图式 37 异腈连续插入的串联反应

Scheme 37 Consecutive insertion of isonitrile

\section{5 总结与展望}

总结了近 15 年来钯催化串联反应合成二氢吲哚及 苯并二氢呋喃衍生物的方法. 其中应用最广泛的是钯催 化环化/偶联反应，而且已经被应用于天然产物的合成 [52]. 另外，钯催化的偶联/环化、Wacker 型和 Catellani 型等反应类型也成功地用于构造取代苯并五元杂环及
其并环. 除此之外，最近发展的新颖方法一步可形成多 个环, 为这类化合物的研究提供了新的途径.

尽管构建苯并五元杂环的方法很多，但反应可靠性 及广谱性、底物的适应性还有待改进; 其次, 只有少数 例子涉及手性合成. 因此，找到新的、有效的手性配体， 实现不对称合成是当前面临的主要问题; 最后，由于传 统偶联会浪费卤原子, 另一方面溶剂的分离、产物纯化 十分繁琐，这些均不符合 “绿色、经济化学” 原则. 离 子液体、聚合物支载、微波促进反应等有利于产物分离 提纯和减少环境污染, 为解决上述问题提供了参考. 相 信随着时间的推移、研究的深入, 这些难题将逐一被解 决, 为这类化合物的合成提供更加有效的选择.

\section{References}

[1] Luize, P. S.; Ueda-Nakamura, T.; Filho, B. P. D.; Cortez, D. A. G.; Nakamura, C. V. Biol. Pharm. Bull. 2006, 29, 2126.

[2] Galliford, C. V.; Scheidt, K. A. Angew. Chem., Int. Ed. 2007, 46, 8748.

[3] Li, H.; Ding, C.; Xu, B.; Hou, X. Acta Chim. Sinica 2014, 72, 765 (in Chinese)

(李浩, 丁昌华, 许斌, 侯雪龙, 化学学报, 2014, 72, 765.)

[4] Liu, J.; Zhu, Q.; Du, J.; Zhang, X. Chin. J. Org. Chem. 2015, 35, 15 (in Chinese).

(刘杰, 朱庆仁, 杜鹃, 张袖丽, 有机化学, 2015, 35, 15.)

[5] Ni, C.; Shen, A.; Cao, Y.; Ye, X. Chin. J. Org. Chem. 2014, 34, 278 (in Chinese)

(倪晨, 沈安, 曹育才, 叶晓峰, 有机化学, 2014, 34, 278.)

[6] Ni, C.; Zhu, L.; Hu, J. Acta Chim. Sinica 2015, 73, 90 (in Chinese). (倪传法, 朱林桂, 胡金波, 化学学报, 2015, 73, 90.)

[7] Xiao, Y.; Pan, Q.; Zhang, X. Acta Chim. Sinica 2015, 73, 383 (in Chinese).

(肖玉兰, 潘强, 张新刚, 化学学报, 2015, 73, 383.)

[8] Zhang, J.; Lu, Q.; Liu, C.; Lei, A. Chin. J. Org. Chem. 2015, 35, 743 (in Chinese) (张剑，陆庆全，刘超，雷爱文，有机化学，2015, 35, 743.)

[9] Zhang, Y.; Feng, B. Chin. J. Org. Chem. 2014, 34, 2406 (in Chinese). (张艳, 冯柏年, 有机化学, 2014, 34, 2406.)

[10] Bai, D.; Li, C.; Li, J.; Jia, X. Chin. J. Org. Chem. 2012, 32, 994 (in Chinese). (白东虎, 李春举, 李健, 贾学顺, 有机化学, 2012, 32, 994.)

[11] Fang, S.; Lü, M.; Long, Y.; Yang, D. Chin. J. Org. Chem. 2011, 31, 1573 (in Chinese). (方晒，吕梅香，龙玉华，杨定乔，有机化学，2011，31，1573.)

[12] Tang, S.; Liang, Y.; Liu, W.-J.; Li, J.-H. Chin. J. Org. Chem. 2004, 24, 1133 (in Chinese) (唐石, 梁云, 林文杰, 李金恒, 有机化学, 2004, 24, 1133.)

[13] Wang, N. Chin. J. Org. Chem. 2011, 31, 1319 (in Chinese). (王乃兴, 有机化学, 2011, 31, 1319.)

[14] Culkin, D. A.; Hartwig, J. F. Acc. Chem. Res. 2003, 36, 234

[15] Ritleng, V.; Sirlin, C.; Pfeffer, M. Chem. Rev. 2002, 102, 1731.

[16] Gang, F.; Xu, G.; Dong, T.; Yang, L.; Du, Z. Chin. J. Org. Chem. 2015, 35, 1428 (in Chinese).

(刚芳莉, 徐光利, 董涛生, 杨丽, 杜正银, 有机化学, 2015, 35, 1428.)

[17] Sheng, R.-L.; Tang, S.; Zhou, D.; Li, Z.-H.; Fu, M.-J.; Jie, L.; Li, S.-H. Synthesis 2015, 47, 1567. 
[18] Gansauer, A.; Hildebrandt, S.; Michelmann, A.; Dahmen, T.; von Laufenberg, D.; Kube, C.; Fianu, G. D.; Flowers, R. A. Angew. Chem., Int. Ed. 2015, 54, 7003.

[19] Wei, X.-H.; Wu, Q.-X.; Yang, S.-D. Synlett 2015, 26, 1417.

[20] Fu, W.; Xu, F.; Fu, Y.; Zhu, M.; Yu, J.; Xu, C.; Zou, D. J. Org. Chem. 2013, 78, 12202.

[21] Grigg, R.; Sansano, J. M.; Santhakumar, V.; Sridharan, V.; Thangavelanthum, R.; Thornton-Pett, M.; Wilson, D. Tetrahedron 1997, 53, 11803.

[22] Grigg, R.; Sridharan, V. Tetrahedron 1999, 576, 65.

[23] Wei, H.-L. Ph.D. Dissertation, Lanzhou University, Lanzhou, 2010 (in Chinese).

(韦海龙, 博士论文, 兰州大学, 兰州, 2010.)

[24] Shen, J.; Cheng, G.; Cui, X. Prog. Chem. 2012, 24, 1324 (in Chinese).

(沈金海, 程国林, 崔秀灵, 化学进展, 2012, 24, 1324.)

[25] Li, J.-H.; Song, R.-J.; Liu, Y.; Xie, Y.-X. Synthesis 2015, 47, 1195.

[26] Fretwell, P.; Grigg, R.; Sansano, J. M.; Sridharan, V.; Sukirthalingam, S.; Wilsona, D.; Redpathb, J. Tetrahedron 2000, 56,7525 .

[27] Casaschi, A.; Grigg, R.; Sansano, J. M. Tetrahedron 2000, 56, 7553.

[28] Jeffery, T. Tetrahedron 1996, 52, 10113.

[29] Casaschi, A.; Grigg, R.; Sansano, J. M.; Wilsona, D.; Redpathb, J. Tetrahedron 2000, 56, 7541.

[30] Grigg, R.; MacLachlan, W. S.; MacPherson, D. T.; Sridharan, V.; Suganthan, S. Tetrahedron 2001, 57, 10335.

[31] Anwar, U.; Fielding, M. R.; Grigg, R.; Sridharan, V.; Urch, C. J. J. Org. Chem. 2006, 691, 1476.

[32] Szlosek-Pinaud, M.; Diaz, P.; Martinez, J.; Lamaty, F. Tetrahedron 2007, 63, 3340.

[33] Grigg, R.; Mariani, E.; Sridharan, V. Tetrahedron Lett. 2001, 42, 8677.

[34] Szlosek-Pinaud, M.; Diaz, P.; Martinez, J.; Lamaty, F. Tetrahedron Lett. 2003, 44, 8657.

[35] Yanada, R.; Obika, S.; Inokuma, T.; Yanada, K.; Yamashita, M.; Ohta, S.; Takemoto, Y. J. Org. Chem. 2005, 70, 6972.

[36] Packer, G.; Lepre, K.; Kankanala, J.; Sridharan, V. RSC Adv. 2014, 4, 3457.

[37] Liu, P.; Huang, L.; Lu, Y.; Dilmeghani, M.; Baum, J.; Xiang, T.; Adams, J.; Tasker, A.; Larsen, R.; Faul, M. M. Tetrahedron Lett. 2007, 48, 2307.

[38] Kim, H. S.; Lee, H. S.; Kim, S. H.; Kim, J. N. Tetrahedron Lett. 2009, 50, 3154.

[39] Day, J.; Frederickson, M.; Hogg, C.; Johnson, C.; Meek, A.; Northern, J.; Reader, M.; Reid, G. Synlett 2015, 26, 2570.

[40] Grigg, R.; Savic, V.; Sridharan, V.; Terrier, C. Tetrahedron 2002, 58,8613 .

[41] Jaegli, S.; Erb, W.; Retailleau, P.; Vors, J. P.; Neuville, L.; Zhu, J. Chem. Eur. J. 2010, 16, 5863 .

[42] Seashore-Ludlow, B.; Somfai, P. Org. Lett. 2010, 12, 3732.

[43] Liu, X.; Li, B.; Gu, Z. J. Org. Chem. 2015, 80, 7547.

[44] René, O.; Lapointe, D.; Fagnou, K. Org. Lett. 2009, 11, 4560.

[45] Kim, H. S.; Gowrisankar, S.; Kim, S. H.; Kim, J. N. Tetrahedron Lett. 2008, 49, 3858.

[46] Ruck, R. T.; Huffman, M. A.; Kim, M. M.; Shevlin, M.; Kandur, W V.; Davies, I. W. Angew. Chem., Int. Ed. 2008, 47, 4711.

[47] Piou, T.; Neuville, L.; Zhu, J. Angew. Chem., Int. Ed. 2012, 51, 11561.

[48] Piou, T.; Neuville, L.; Zhu, J. Org. Lett. 2012, 14, 3760.

[49] Piou, T.; Bunescu, A.; Wang, Q.; Neuville, L.; Zhu, J. Angew. Chem., Int. Ed. 2013, 52, 12385.
[50] Bunescu, A.; Piou, T.; Wang, Q.; Zhu, J. Org. Lett. 2015, 17, 334.

[51] Wang, W.; Zhou, R.; Jiang, Z.-J.; Wang, X.; Fu, H.-Y.; Zheng, X.-L.; Chen, H.; Li, R.-X. Eur. J. Org. Chem. 2015, 2015, 2579.

[52] Pinto, A.; Jia, Y.; Neuville, L.; Zhu, J. Eur. Chem. J. 2007, 13, 961.

[53] Lee, H.-S.; Kim, K.-H.; Lim, J.-W.; Kim, J.-N. Bull. Korean Chem. Soc. 2011, 32, 1083.

[54] Kamisaki, H.; Yasui, Y.; Takemoto, Y. Tetrahedron Lett. 2009, 50, 2589.

[55] Hande, S. M.; Nakajima, M.; Kamisaki, H.; Tsukano, C.; Takemoto, Y. Org. Lett. 2011, 13, 1828.

[56] Newman, S. G.; Lautens, M. J. Am. Chem. Soc. 2011, 133, 1778.

[57] Liu, X.; Ma, X.; Huang, Y.; Gu, Z. Org. Lett. 2013, 15, 4814.

[58] Jiang, T. S.; Tang, R. Y.; Zhang, X. G.; Li, X. H.; Li, J. H. J. Org. Chem. 2009, 74, 8834.

[59] Jaegli, S.; Dufour, J.; Wei, H. L.; Piou, T.; Duan, X. H.; Vors, J. P.; Neuville, L.; Zhu, J. Org. Lett. 2010, 12, 4498.

[60] Wu, T.; Mu, X.; Liu, G. Angew. Chem., Int. Ed. 2011, 50, 12578.

[61] Mu, X.; Wu, T.; Wang, H. Y.; Guo, Y. L.; Liu, G. J. Am. Chem. Soc. 2012, 134, 878.

[62] Kamijo, S.; Sasaki, Y.; Kanazawa, C.; Schüßeler, T.; Yamamoto, Y. Angew. Chem., Int. Ed. 2005, 44, 7718.

[63] Miura, T.; Toyoshima, T.; Ito, Y.; Murakami, M. Chem. Lett. 2009, $38,1174$.

[64] Miura, T.; Toyoshima, T.; Takahashi, Y.; Murakami, M. Org. Lett. 2009, 11, 2141.

[65] Toyoshima, T.; Mikano, Y.; Miura, T.; Murakami, M. Org. Lett. 2010, $12,4584$.

[66] Lira, R.; Wolfe, J. P. J. Am. Chem. Soc. 2004, 126, 13906.

[67] Schultz, D. M.; Wolfe, J. P. Org. Lett. 2010, 12, 1208.

[68] Thansandote, P.; Hulcoop, D. G.; Langer, M.; Lautens, M. J. Org. Chem. 2009, 74, 1673.

[69] Cacchi, S.; Fabrizi, G.; Goggiamani, A.; Sferrazza, A. Org. Biomol. Chem. 2011, 9, 1727.

[70] Houlden, C. E.; Bailey, C. D.; Ford, J. G.; Gagne, M. R.; Lloyd-Jones, G. C.; Booker-Milburn, K. I. J. Am. Chem. Soc. 2008, 130,10066 .

[71] Agasti, S.; Maity, S.; Szabo, K. J.; Maiti, D. Adv. Synth. Catal. 2015, 357, 2331.

[72] Pinto, A.; Neuville, L.; Zhu, J. Angew. Chem., Int. Ed. 2007, 46, 3291.

[73] Tang, S.; Peng, P.; Pi, S. F.; Liang, Y.; Wang, N. X.; Li, J. H. Org. Lett. 2008, 10, 1179.

[74] Tang, S.; Peng, P.; Wang, Z.-Q.; Tang, B.-X.; Deng, C.-L.; Li, J.-H.; Zhong, P.; Wang, N.-X. Org. Lett. 2008, 10, 1875.

[75] An, G.; Zhou, W.; Zhang, G.; Sun, H.; Han, J.; Pan, Y. Org. Lett. 2010, $12,4482$.

[76] Wang, J. Y.; Su, Y. M.; Yin, F.; Bao, Y.; Zhang, X.; Xu, Y. M.; Wang, X. S. Chem. Commun. 2014, 50, 4108.

[77] Nicolai, S.; Erard, S.; Gonzalez, D. F.; Waser, J. Org. Lett. 2010, $12,384$.

[78] Yip, K.-T.; Yang, M.; Law, K.-L.; Zhu, N.-Y.; Yang, D. J. Am. Chem. Soc. 2006, 128, 3130.

[79] Yip, K. T.; Zhu, N. Y.; Yang, D. Org. Lett. 2009, 11, 1911.

[80] He, W.; Yip, K.-T.; Zhu, N.-Y.; Yang, D. Org. Lett. 2009, 11, 5626.

[81] Du, W.; Gu, Q.; Li, Z.; Yang, D. J. Am. Chem. Soc. 2015, 137, 1130.

[82] Mariampillai, B.; Alberico, D.; Bidau, V.; Lautens, M. J. Am. Chem. Soc. 2006, 128, 14436.

[83] Rudolph, A.; Rackelmann, N.; Turcotte-Savard, M.-O.; Lautens, M. J. Org. Chem. 2009, 74, 289.

[84] Wu, X. X.; Zhou, P. X.; Wang, L. J.; Xu, P. F.; Liang, Y. M. Chem. 
Commun. 2014, 50, 3882.

[85] Thansandote, P.; Raemy, M.; Rudolph, A.; Lautens, M. Org. Lett. 2007, $9,5255$.

[86] Muñiz, K. J. Am. Chem. Soc. 2007, 129, 14543.

[87] Ying, A.-G.; Ye, W.-D.; Liu, L.; Wu, G.-F.; Chen, X.-Z.; Qian, S.; Zhang, Q.-P. Chin. J. Org. Chem. 2008, 28, 2081 (in Chinese). (应安国, 叶伟东, 刘泺, 吴国峰, 陈新志, 钱胜, 张秋萍, 有机 化学, 2008, 28, 2081.)

[88] John, J.; Indu, U.; Suresh, E.; Radhakrishnan, K. V. J. Am. Chem. Soc. 2009, 131, 5402.

[89] Prakash, P.; Jijy, E.; Preethanuj, P.; Pihko, P. M.; Sarath Chand, S.;
Radhakrishnan, K. V. Chem. Eur. J. 2013, 19, 10473.

[90] Chand, S. S.; Jijy, E.; Prakash, P.; Szymoniak, J.; Preethanuj, P.; Dhanya, B. P.; Radhakrishnan, K. V. Org. Lett. 2013, 15, 3338.

[91] Ramirez, T. A.; Wang, Q.; Zhu, Y.; Zheng, H.; Peng, X.; Cornwall, R. G.; Shi, Y. Org. Lett. 2013, 15, 4210.

[92] Zheng, H.; Zhu, Y.; Shi, Y. Angew. Chem., Int. Ed. 2014, 53, 11280.

[93] Campbell, C. D.; Greenaway, R. L.; Holton, O. T.; Chapman, H. A.; Anderson, E. A. Chem. Commun. 2014, 50, 5187.

[94] Senadi, G. C.; Hu, W. P.; Boominathan, S. S.; Wang, J. J. Chem. Eur. J. 2015, 21, 998. 